\title{
Novel Dihydro-1,3,2H-benzoxazine Derived from Furfurylamine: Crystal Structure, Hirshfeld Surface Analysis, Photophysical Property, and Computational Study
}

\author{
Worawat Wattanathana ${ }^{1, * \mathbb{D}}$, Yuranan Hanlumyuang ${ }^{1}$, Suttipong Wannapaiboon ${ }^{2} \mathbb{D}$, Kantapat Chansaenpak ${ }^{3}$, \\ Piyanut Pinyou ${ }^{4}{ }^{\oplus}$, Tanin Nanok ${ }^{5}$ and Pongsakorn Kanjanaboos ${ }^{6}$ \\ 1 Department of Materials Engineering, Faculty of Engineering, Kasetsart University, \\ Bangkok 10900, Thailand; yuranan.h@ku.th \\ 2 Synchrotron Light Research Institute, 111 University Avenue, Nakhon Ratchasima 30000, Thailand; \\ suttipong@slri.or.th \\ 3 National Nanotechnology Center, National Science and Technology Development Agency, Thailand Science \\ Park, Pathum Thani 12120, Thailand; kantapat.cha@nanotec.or.th \\ 4 School of Chemistry, Institute of Science, Suranaree University of Technology, 111 University Avenue, \\ Nakhon Ratchasima 30000, Thailand; piyanutp@sut.ac.th \\ 5 Department of Chemistry, Faculty of Science, Kasetsart University, Bangkok 10900, Thailand; fscitnn@ku.ac.th \\ 6 School of Materials Science and Innovation, Faculty of Science, Mahidol University, Bangkok 10400, Thailand; \\ pongsakorn.kan@mahidol.edu \\ check for \\ updates \\ Citation: Wattanathana, W.; \\ * Correspondence: fengwwwa@ku.ac.th
}

Hanlumyuang, Y.; Wannapaiboon, S.; Chansaenpak, K.; Pinyou, P.; Nanok,

T.; Kanjanaboos, P. Novel

Dihydro-1,3,2H-benzoxazine Derived

from Furfurylamine: Crystal

Structure, Hirshfeld Surface Analysis,

Photophysical Property, and

Computational Study. Crystals 2021

11, 568. https://doi.org/10.3390/

cryst11050568

Academic Editors:

Waldemar Maniukiewicz and Ana

M. Garcia-Deibe

Received: 29 March 2021

Accepted: 13 May 2021

Published: 20 May 2021

Publisher's Note: MDPI stays neutral with regard to jurisdictional claims in published maps and institutional affiliations.

Copyright: (c) 2021 by the authors Licensee MDPI, Basel, Switzerland. This article is an open access article distributed under the terms and conditions of the Creative Commons Attribution (CC BY) license (https:// creativecommons.org/licenses/by/ $4.0 /)$
Abstract: Dihydro-1,3,2H-benzoxazines (or benzoxazine monomers) are a class of compounds that have been widely utilized in many areas such as the production of the functional polymers and optoelectronic materials. The structure variety of the benzoxazines plays a vital role in their desired properties. The effort of synthesizing functionalized benzoxazines from bioresources is of interest for sustainable development. Herein, we report the synthesis of the novel benzoxazine monomer referred to as 3-(furan-2-ylmethyl)-6-methyl-3,4-dihydro-2H-benzo[ $e][1,3]$ oxazine or benzoxazine (I) from a one-pot Mannich reaction using $p$-cresol, paraformaldehyde, and furfurylamine (a bio-derived amine). An X-ray crystallographic study was performed at low temperature (100 K) to obtain the structural characteristics of the benzoxazine (I). The result reveals that the oxazine ring adopts a half chair conformation to locate all the members of the benzoxazine ring as planar as possible by employing the expansion of the bond angles within the ring. Apart from the structural parameters, the intermolecular interactions were also examined. It was found that the significant interactions within the crystal are $\mathrm{C}-\mathrm{H} \cdots \mathrm{N}, \mathrm{C}-\mathrm{H} \cdots \mathrm{O}$, and the $\mathrm{C}-\mathrm{H} \cdots \pi$ interactions. The $\mathrm{C}-\mathrm{H} \cdots \mathrm{N}$ interactions link the benzoxazine (I) molecules into an infinite molecular chain, propagating along the [100] direction. Hirshfeld surfaces and their corresponding fingerprint plots were comprehensively analyzed to confirm and quantify the significance of these interactions. Moreover, the photophysical properties of the benzoxazine (I) were investigated in solvents with various polarities. The corresponding relations between the structural features, frontier molecular orbitals, and absorption-and-emission characteristics were proposed and explained according to the DFT and TD-DFT calculations.

Keywords: crystal structure; Hirshfeld surface analysis; photophysical properties; benzoxazine

\section{Introduction}

Dihydrobenzoxazines are versatile compounds used in many areas such as thermoset manufacture [1-3], optoelectronic materials [4,5], antimicrobial agents [6-10], and medicinal applications [11-13]. Among different isomers of dihydrobenzoxazines (Scheme 1), 3,4dihydro-1,3,2H-benzoxazines (or benzoxazine monomers) are the most common as they can be readily synthesized by Mannich reactions using three reagents, namely phenols, 
paraformaldehyde, and amines. A variety of starting materials can be used in benzoxazine syntheses, leading to their exceptional flexibility in terms of the molecular design. This flexible molecular design allows scientists and engineers to form numerous novel benzoxazines as well as polybenzoxazines with many prominent characteristics, such as distinctive thermal stabilities [14-19], good mechanical strengths [19,20], desirable dielectric properties [21-24], and high anticorrosion performances [25-30]. These advantages make the benzoxazine resins promising candidates for applications, such as reinforcement composites and anticorrosion coatings. Additionally, benzoxazines possess interesting optical properties, i.e., photochromism [31], electrochromism [32], and photoluminescence [33]. It should be noted that the optical properties of benzoxazine- and polybenzoxazine-based materials have not been reported as much as the other properties mentioned earlier.<smiles>c1ccc2c(c1)CCNO2</smiles>

(a)<smiles>c1ccc2c(c1)CCON2</smiles>

(d)<smiles>c1ccc2c(c1)CNCO2</smiles>

(b)<smiles>c1ccc2c(c1)COCN2</smiles>

(e)<smiles>c1ccc2c(c1)NCCO2</smiles>

(c) $\mathrm{H}$<smiles>c1ccc2c(c1)CNOC2</smiles>

(f)

Scheme 1. Several structural isomers of dihydrobenzoxazines: (a) 3,4-dihydro-2H-benzo[e][1,2] oxazine, (b) 3,4-dihydro-2H-benzo[e][1,3] oxazine, (c) 3,4-dihydro-2H-benzo[b][1,4]oxazine, (d) 3,4dihydro-1H-benzo[c][1,2]oxazine, (e) 2,4-dihydro-1H-benzo[d][1,3]oxazine, and (f) 3,4-dihydro- $1 H$ benzo[ $[d][1,2]$ oxazine.

Although the availability of the feedstocks for benzoxazine production is extremely high, most of them are derived from nonrenewable resources, namely the so-called petroleum-based chemicals. Therefore, the search for potential raw materials from renewable resources is highly desirable for long-term sustainability. Among the three starting substances for benzoxazine productions, only phenol and amine derivatives can be obtained from natural resources. Recently, there are several reports on the fabrication of benzoxazines and polybenzoxazines via bio-based phenol sources [34-41]. Moreover, the utilization of bio-derived primary amines in the structural design of benzoxazines such as stearylamine [37], dehydroabietylamine [42], and furfurylamine [40,41,43,44] have been reported. Among different bio-based primary amines, furfurylamine has been ubiquitously employed in the preparation of benzoxazines and polybenzoxazines since it can be straightforwardly synthesized from furfural, one of the 10 value-added bio-based substance reported by the U.S. Department of Energy [45]. For this reason, the furfurylamine-derived benzoxazines are likely to be the prospective materials for developing novel polybenzoxazine resins. Even though several research groups have reported the syntheses and certain physical properties such as thermal stabilities and mechanical properties, no report on the optical properties has been found. This work aims to prepare the benzoxazine (I), 3-[(furan-2-yl)methyl]-6-methyl-3,4-dihydro-2H-1,3-benzoxazine, from furfurylamine as a model benzoxazine monomer to examine its photophysical properties. Here, the crystal structure of the benzoxazine (I) is thoroughly examined to observe the significant structural features and intermolecular interactions related to its properties and reactivity. In addition, quantum chemical calculations on frontier molecular orbitals and optimized structural parameters are carried out and identified to investigate the mechanism of the photo-absorption and emission of the benzoxazine (I). 


\section{Materials and Methods}

\subsection{Synthesis of the Benzoxazine (I)}

The benzoxazine monomer, 3-[(furan-2-yl)methyl]-6-methyl-3,4-dihydro-2H-1, 3-benzoxazine, was prepared by a one-pot Mannich reaction like the syntheses of other derivatives reported in the literature $[33,46,47]$. Herein, furfurylamine (Alfa Aesar, Haverhill, MA, USA, $2.43 \mathrm{~g}, 25 \mathrm{mmol}$ ), paraformaldehyde (Merck, Kenilworth, NJ, USA, $1.50 \mathrm{~g}$, $50 \mathrm{mmol}$ ), and para-cresol (Merck, $2.71 \mathrm{~g}, 25 \mathrm{mmol}$ ) were dissolved in dioxane (RCI Labscan, Bangkok, Thailand, $25 \mathrm{~mL}$ ). The mixture was refluxed for $6 \mathrm{~h}$ to obtain a clear dark yellow solution. The solvent was removed by a rotary evaporator to obtain a brown liquid. To remove impurities, $25 \mathrm{~mL}$ of dichloromethane was added to the brown liquid; the obtained solution was extracted by $3 \mathrm{~N} \mathrm{NaOH}(25 \mathrm{~mL})$ for three times and subsequently by $25 \mathrm{~mL}$ of deionized water for three times. The extracted product of the benzoxazine (I) was dried using anhydrous sodium sulfate (Ajax Finechem, Wollongong, Australia). The anhydrous sodium sulfate was removed by decantation. Then, the dichloromethane solvent was removed by a rotary evaporator and consequently, the viscous brown liquid of the benzoxazine (I) was obtained.

\subsection{Single-Crystal X-ray Diffraction (SC-XRD)}

Colorless crystals of the benzoxazine (I) were obtained after leaving the viscous liquid at ambient atmosphere for several months. A single crystal of the benzoxazine (I) was selected under an optical microscope and mounted on the crystal holder. The diffraction patterns from the single crystal of the benzoxazine (I) were collected at $100 \mathrm{~K}$ on a Bruker APEX II diffractometer using Mo K $\alpha$ radiation $(\lambda=0.71073 \AA)$. Cell refinement and data reduction were carried out by SAINT [48]. Absorption correction was done by the multiscan method using SADABS [49]. Using Olex2 [50], the structure was solved by the ShelXT [51] structure solution program using the intrinsic phasing method and then refined by the ShelXL [52] refinement package using a least-squares minimization. All nonhydrogen atoms were treated anisotropically. The $\mathrm{C}$-bound $\mathrm{H}$ atoms were placed in idealized positions ( $\mathrm{C}-\mathrm{H}=0.95-1.00 \AA$ Adepending on hybridization) and refined as riding atoms. The methyl groups were allowed to rotate-but not to tip-in order to best fit the electron density. The constraint $U_{\text {iso }}(\mathrm{H})=1.2 U_{\mathrm{eq}}$ (carrier) or $1.5 U_{\mathrm{eq}}$ (methyl $\mathrm{C}$ ) was applied in all cases. It should be noted that the absolute structure of the benzoxazine (I) was indeterminate in the present refinement. The Mercury software package (Version 2020.1) [53] was used to prepare molecular graphics and materials for publication. A summary of the crystallographic data for the benzoxazine (I) is given in Table 1. 
Table 1. Crystal data and structure refinement details for the benzoxazine (I).

\begin{tabular}{|c|c|}
\hline $\begin{array}{c}\text { Crystallographic Data and Structural } \\
\text { Refinement Details }\end{array}$ & Benzoxazine (I) \\
\hline CCDC number & 2015006 \\
\hline Empirical formula & $\mathrm{C}_{14} \mathrm{H}_{15} \mathrm{NO}_{2}$ \\
\hline Formula weight & 229.27 \\
\hline Temperature/K & 100.0 \\
\hline Crystal system & orthorhombic \\
\hline Space group & $\mathrm{P} 2{ }_{1} 2{ }_{1} 2_{1}$ \\
\hline $\mathrm{a} / \AA$ & $5.4704(3)$ \\
\hline $\mathrm{b} / \AA$ & $9.6887(6)$ \\
\hline $\mathrm{c} / \AA$ & $22.2293(16)$ \\
\hline$\alpha /^{\circ}$ & 90 \\
\hline$\beta /{ }^{\circ}$ & 90 \\
\hline$\gamma /{ }^{\circ}$ & 90 \\
\hline Volume $/ \AA^{3}$ & $1178.18(13)$ \\
\hline $\mathrm{Z}$ & 4 \\
\hline$\rho_{\text {calc }} \mathrm{g} / \mathrm{cm}^{3}$ & 1.293 \\
\hline$\mu / \mathrm{mm}^{-1}$ & 0.087 \\
\hline $\mathrm{F}(000)$ & 488.0 \\
\hline Crystal size $/ \mathrm{mm}^{3}$ & $0.38 \times 0.06 \times 0.06$ \\
\hline Radiation & $\operatorname{Mo~K}_{\alpha}(\lambda=0.71073)$ \\
\hline $2 \Theta$ range for data collection $/{ }^{\circ}$ & 5.578 to 56.518 \\
\hline Index ranges & $-7 \leq \mathrm{h} \leq 4,-12 \leq \mathrm{k} \leq 7,-28 \leq 1 \leq 29$ \\
\hline Reflections collected & 6314 \\
\hline Independent reflections & $2898\left[R_{\text {int }}=0.0408, R_{\text {sigma }}=0.0698\right]$ \\
\hline Data/restraints/parameters & $2898 / 0 / 155$ \\
\hline Goodness-of-fit on $\mathrm{F}^{2}$ & 1.053 \\
\hline Final $R$ indexes $[\mathrm{I}>=2 \sigma(\mathrm{I})]$ & $\mathrm{R}_{1}=0.0492, \mathrm{w} \mathrm{R}_{2}=0.0970$ \\
\hline Final $\mathrm{R}$ indexes [all data] & $\mathrm{R}_{1}=0.0710, \mathrm{w} \mathrm{R}_{2}=0.1073$ \\
\hline Largest diff. peak/hole/e $\AA^{-3}$ & $0.25 /-0.23$ \\
\hline
\end{tabular}

\subsection{Characterization of the Benzoxazine (I)}

Chemical functional groups of the benzoxazine (I) were examined by Fourier-transform Raman (FT-Raman) spectroscopy. The FT-Raman spectrum was recorded by the Fouriertransform Raman spectrophotometer (Horiba, LabRAM HR Evolution model) using a red laser with a wavelength of $785 \mathrm{~nm}$ in the range of $4000-200 \mathrm{~cm}^{-1}$. The acquisition time per step was set to $5 \mathrm{~s}$, and the spectral data were the average value from 10 accumulated scans. The FT-IR spectrum was collected by the Fourier-transform infrared spectrophotometer (Perkin Elmer, Spectrum 100 model), which was carried out in an ATR mode. Both the background and sample signal were scanned for 100 times using a spectral resolution of $2 \mathrm{~cm}^{-1}$. To elucidate the structure of the benzoxazine (I), nuclear magnetic resonance (NMR spectrometer, Bruker AVANCE III $500 \mathrm{MHz}$ for ${ }^{1} \mathrm{H}$ and $126 \mathrm{MHz}$ for ${ }^{13} \mathrm{C}$ ) was used to perform ${ }^{1} \mathrm{H}$-NMR and ${ }^{13} \mathrm{C}-\mathrm{NMR}$ studies. The benzoxazine (I) was dissolved in $\mathrm{CDCl}_{3}$ prior to the NMR investigation. Electrospray-ionization mass spectrometer (ESI-MS, Bruker micrOTOF spectrometer) was employed to measure the molecular weight of the benzoxazine (I). The powder X-ray diffraction (PXRD) was carried out at Beamline 1.1W (Synchrotron Light Research Institute, Thailand) using monochromatic X-ray with an energy of $12 \mathrm{keV}$.

Characterization results: ${ }^{1} \mathrm{H}-\mathrm{NMR}\left(500 \mathrm{MHz}, \mathrm{CDCl}_{3}, \delta_{\mathrm{H}}\right.$ in ppm): $2.35(\mathrm{~s}, 3 \mathrm{H}), 4.02$ $(\mathrm{s}, 2 \mathrm{H}), 4.08(\mathrm{~s}, 2 \mathrm{H}), 4.95(\mathrm{~s}, 2 \mathrm{H}), 6.35(\mathrm{~d}, J=3.0 \mathrm{~Hz}, 1 \mathrm{H}), 6.44(\mathrm{dd}, J=3.5,2.0 \mathrm{~Hz}, 1 \mathrm{H})$, $6.82(\mathrm{~d}, J=8.5 \mathrm{~Hz}, 1 \mathrm{H}), 6.86(\mathrm{~s}, 1 \mathrm{H}), 7.04(\mathrm{dd}, J=8.0,2.0 \mathrm{~Hz}, 1 \mathrm{H}), 7.15(\mathrm{~d}, J=1.0 \mathrm{~Hz}, 1 \mathrm{H})$ (Figure S1, Supplementary Materials); ${ }^{13} \mathrm{C}-\mathrm{NMR}\left(126 \mathrm{MHz}, \mathrm{CDCl}_{3}, \delta_{\mathrm{C}}\right.$ in ppm): 20.58, 48.22, 49.57, 81.78, 108.91, 110.19, 116.24, 119.28, 127.93, 128.40, 130.01, 142.56, 151.71, 151.75 (Figure S2, Supplementary Materials); ESI-MS: $[\mathrm{M}+\mathrm{Na}]^{+}=252.0995 \mathrm{amu}$ (Figure S3, Supplementary Materials); FT-Raman ( $\left.\mathrm{cm}^{-1}\right)$ : 3067 (w, $\left.\mathrm{C}_{\text {aromatic }}-\mathrm{H}\right), 2984\left(\mathrm{w}, \mathrm{C}_{\mathrm{sp}}{ }^{3}-\mathrm{H}\right), 2921$ $\left(\mathrm{w}, \mathrm{C}_{\mathrm{sp}}{ }^{3}-\mathrm{H}\right), 2902\left(\mathrm{w}, \mathrm{C}_{\mathrm{sp}}{ }^{3}-\mathrm{H}\right), 1505$ (vs, oxazine ring vibration) (Figure S4, Supplemen- 
tary Materials); FT-IR ( $\left.\mathrm{cm}^{-1}\right): 3084\left(\mathrm{w}, \mathrm{C}_{\text {aromatic }}-\mathrm{H}\right), 2983\left(\mathrm{w}, \mathrm{C}_{\mathrm{sp}}{ }^{3}-\mathrm{H}\right), 2921\left(\mathrm{w}, \mathrm{C}_{\mathrm{sp}}{ }^{3}-\mathrm{H}\right)$, 2903 (w, C sp $\left.^{3}-\mathrm{H}\right), 1500$ (vs, oxazine ring vibration) (Figure S5, Supplementary Materials); PXRD (12 keV): The experimental PXRD diffractogram was similar to the calculated PXRD data generated from the SC-XRD results (Figure S6, Supplementary Materials).

\subsection{Photophysical Studies}

The stock solutions of the benzoxazine (I) with the concentration of $2.9 \mathrm{mM}$ in various solvents, namely, dioxane, chloroform, ethyl acetate (EtOAc), tetrahydrofuran (THF), dichloromethane (DCM), N,N-dimethyl formamide (DMF), acetonitrile (ACN), ethanol $(\mathrm{EtOH})$, methanol $(\mathrm{MeOH})$, and water, were done by dissolving $10 \mathrm{mg}$ of the benzoxazine (I) in the solvents and then adjusting the volume to $15 \mathrm{~mL}$ using a volumetric flask. All organic solvents used in this work were obtained from Honeywell. The stock solutions were further diluted to have a concentration of $\approx 20 \mu \mathrm{M}$. For UV-Vis absorption and fluorescence studies, $3 \mathrm{~mL}$ of the diluted solutions was transferred to a quartz cuvette. Then, the absorption spectra were recorded by a Cary Series UV-Vis-NIR spectrophotometer (Agilent Tech, Santa Clara, CA, USA) and a PerkinElmer LS55 fluorescence spectrometer, respectively. The parameters for fluorescence measurement were as follows: excitation wavelengths $=460 \mathrm{~nm}$; excitation slit widths $=10 \mathrm{~nm}$, and emission slit widths $=10 \mathrm{~nm}$.

\subsection{Computational Details}

All DFT and TD-DFT calculations were performed using the Gaussian09 program package [54]. The ground state geometrical structure of the benzoxazine (I) was optimized without constraints by DFT with the B3LYP functional [55-58] and the 6-311+G(d) basis set $[59,60]$ using the initial structure obtained from the crystallographic data. This method gives a good agreement in terms of bond length and bond angle between the X-ray and the gas-phase optimized structure of benzoxazine (I) with the root mean square displacement (RMSD) of the bond lengths and bond angles from the X-ray structure of $0.009 \AA$ and $0.8^{\circ}$, respectively (see Table S1, Supplementary Materials). However, from the superimposition of the X-ray and optimized structure (see Figure S7, Supplementary Materials), one can see the large deviation of atomic positions in the peripheral region (N, C10-C14, and O2). This probably originates from the molecular packing in the solid crystal. The vertical transition energies and geometric optimization in the excited state were calculated by the TD-DFT method at the same level of theory. Both the ground and excited states were calculated in different solvents, namely dioxane, chloroform, ethyl acetate (EtOAc), tetrahydrofuran (THF), dichloromethane (DCM), N,N-dimethylformamide (DMF), acetonitrile (ACN), ethanol $(\mathrm{EtOH})$, methanol $(\mathrm{MeOH})$, and water. All true local minima in the ground and excited states were confirmed by vibrational frequency calculations. The solvent effects were included by means of the polarized continuum model (PCM) approach [61].

\section{Results and Discussion}

\subsection{Molecular Structure, Crystal Packing, and Hirshfeld Surface Analysis}

The molecular structure together with a non-IUPAC labeling scheme of the benzoxazine (I) is displayed in Figure 1. The displacement ellipsoids were drawn at a 50\% probability level. The benzoxazine (I) crystallized in a space group $\mathrm{P} 2{ }_{1} 2{ }_{1} 2{ }_{1}$. The tertiaryamine nitrogen atom (N1) adopted a distorted trigonal pyramidal shape as seen from the expansion of the angles around N1 atom from the theoretical angle of $107^{\circ}$, i.e., C9-N1$\mathrm{C} 10=112.9(2)^{\circ}, \mathrm{C} 8-\mathrm{N} 1-\mathrm{C} 9=108.6(2)^{\circ}$, and $\mathrm{C} 8-\mathrm{N} 1-\mathrm{C} 10=112.0(2)^{\circ}$ [The sum of C-N-C bond angles $=333.5^{\circ}$. The atoms in the benzoxazine ring $(\mathrm{C} 2-\mathrm{C} 9 / \mathrm{N} 1 / \mathrm{O} 1)$ were mostly arranged in a planar orientation, as seen from the RMS deviation of $0.1555 \AA$. The most deviated atom was N1, which had a deviation of 0.387(2) A from the mean plane of the benzoxazine $[62,63]$. Moreover, the peripheral atoms attached to the tertiary $\mathrm{N}$ atom $(\mathrm{C} 10$ $\mathrm{C} 14 / \mathrm{O} 2)$ were also arranged in the same plane (the RMS deviation of $0.0080 \AA$ ). The two mean planes intersected with a dihedral angle of $34.85(1)^{\circ}$. The attempt to locate the members of the 1,3-2H-benzoxazine ring in the same plane made the oxazine ring adapt a half 
chair conformation (the puckering parameters $\theta=50.8^{\circ}$ and $\varphi=254^{\circ}$ ) [64], as evidently observed from the expansion of the $\mathrm{C} 5-\mathrm{O} 1-\mathrm{C} 8$ and $\mathrm{N} 1-\mathrm{C} 8-\mathrm{O} 1$ bond angles to $114.9(2)^{\circ}$ and $114.57(2)^{\circ}$, respectively. The $\mathrm{C}-\mathrm{N}-\mathrm{C}$ bond angles did not expand as much as the other bond angles, making the $\mathrm{N} 1$ atom to be the most deviated atom from the benzoxazine mean plane. The bond lengths concerning the oxazine ring were well agreed with the previous literature's values $[33,65-70]$.

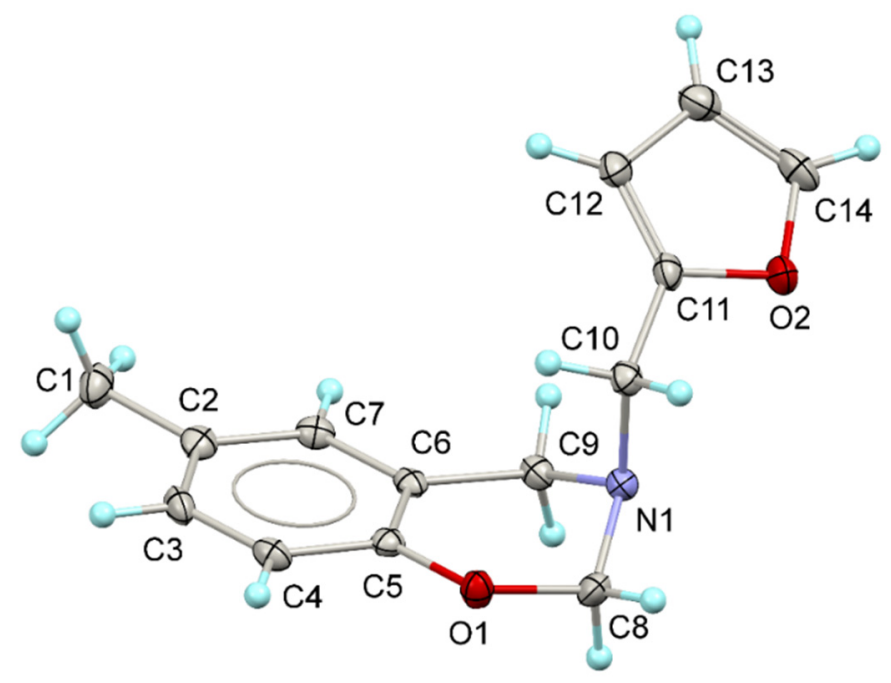

Figure 1. Molecular structures and non-IUPAC labeling scheme of the benzoxazine (I) with displacement ellipsoids drawn at the $50 \%$ probability level.

In the crystal structure, typical intermolecular hydrogen bonds were not observed since the benzoxazine (I) does not have a hydrogen atom bonded to highly electronegative atoms (i.e., F, O, or N). However, several contacts were found in the crystal packing of the benzoxazine (I) (Figure 2). Viewing down towards the [010] direction, the molecules of the benzoxazine (I) were related by a translational symmetry linked together via $\mathrm{C}-\mathrm{H} \cdots \mathrm{N}$ and $\mathrm{C}-\mathrm{H} \cdots \pi$ short contacts (Figure $2 \mathrm{a}$ ). Moreover, the $\mathrm{C}-\mathrm{H} \cdots \mathrm{N}$ contact with the $\mathrm{C}_{1}{ }^{1}(5)$ graph-set motif [71-73] was constructed from the hydrogen atom from the furan moiety (H12) and the tertiary-amine nitrogen atom (N1) (Figure 2b). Apart from the $\mathrm{C}-\mathrm{H} \cdots \mathrm{N}$ contact, the molecules in a similar general position can establish two $\mathrm{C}-\mathrm{H} \cdots \pi$ bonds on the opposite sides of the benzene ring. The first $\mathrm{C}-\mathrm{H} \cdots \pi$ interaction was formed from one of the methylene hydrogens on the carbon that bonded to both the oxygen and nitrogen heteroatoms (H8B) and the centroid of the benzene ring. The second $\mathrm{C}-\mathrm{H} \cdots \pi$ interaction was set up from one of the methyl hydrogens (H1A) and the centroid of the benzene ring. These three interactions joined the benzoxazine (I) molecules into an infinite molecular chain propagating along the [100] direction. Moreover, a $C_{1}{ }^{1}(8) \mathrm{C}-\mathrm{H} \cdots \mathrm{O}$ interaction with the slightly longer distance than the $\mathrm{C}-\mathrm{H} \cdots \mathrm{N}$ contact was observed between the benzoxazine (I) molecules related by a $2{ }_{1}$-screw axis. Geometries of the intermolecular interactions in terms of distances, angles, and symmetry codes are listed in Table 2 . However, no $\pi-\pi$ interaction was found in the crystal structure of the benzoxazine (I). This might be due to the steric hindrance from the methyl substituent on the benzene ring and the furan group blocking the aromatic rings from locating closer together. Therefore, the formation of $\mathrm{C}-\mathrm{H} \cdots \pi$ interactions were more favorable than $\pi-\pi$ interactions. The formation of all four contacts mentioned stabilized the crystal structure of the molecules of the benzoxazine (I). 
(a)

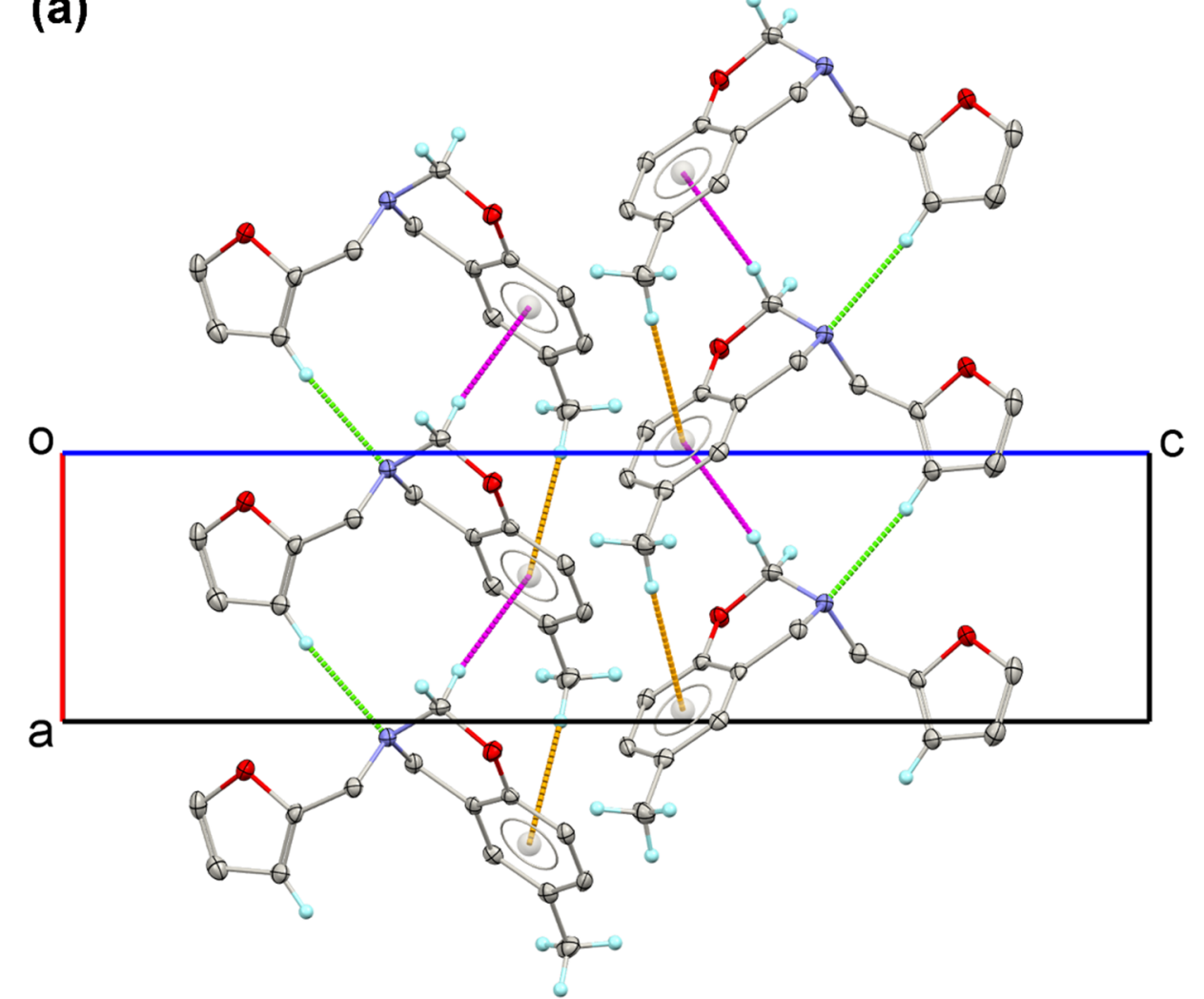

(b)

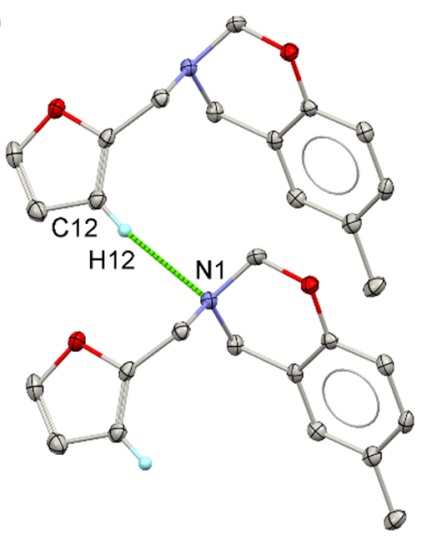

(c)

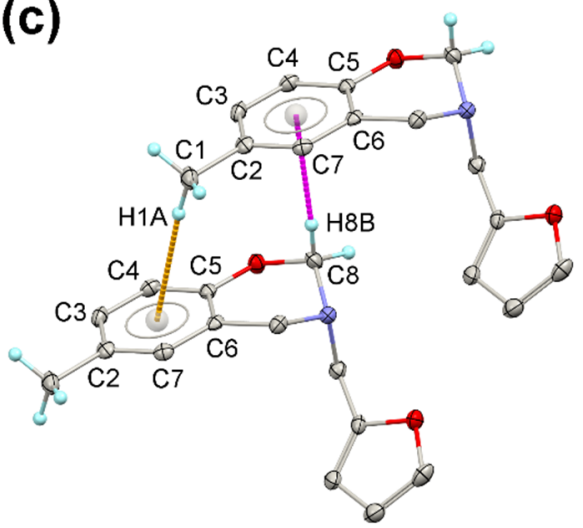

(d)

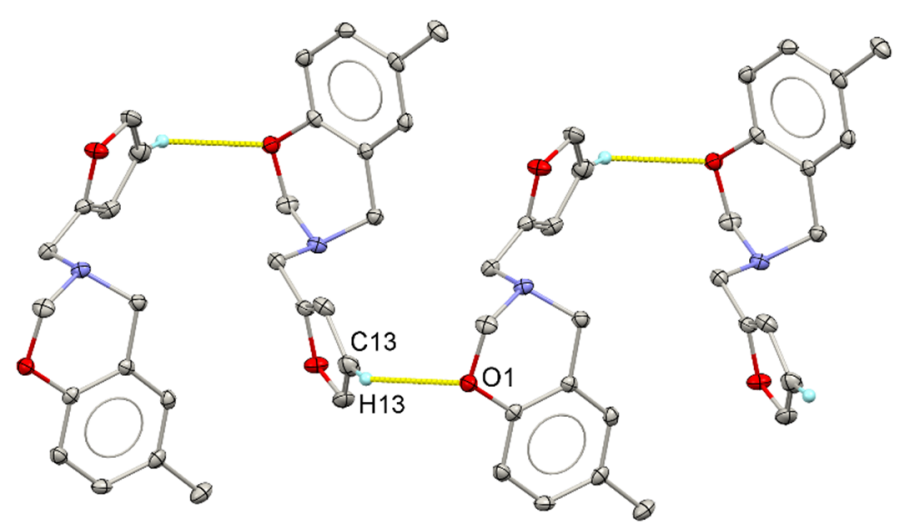

Figure 2. (a) A view down towards a [010] showing a part of an [100] infinite molecular chain of the $\mathrm{C}-\mathrm{H} \cdots \mathrm{N}$ contact (green dash line) and the $\mathrm{C}-\mathrm{H} \cdots \pi$ interactions (orange and magenta dash lines). A closer look at (b) the $\mathrm{C} 12-\mathrm{H} 12 \cdots \mathrm{N} 1$ contact (green dash line), (c) the $\mathrm{C} 1-\mathrm{H} 1 \mathrm{~A} \cdots \mathrm{C}_{g}$ (orange dash line), and the $\mathrm{C} 8-\mathrm{H} 8 \mathrm{~B} \cdots C_{g}$ (magenta dash line). Note that $C_{g}$ is the centroid of the benzene ring (C2 to C7). (d) The $\mathrm{C} 13-\mathrm{H} 13 \cdots \mathrm{O} 1$ contact shown in yellow dash line. 
Table 2. Geometries of $\mathrm{C}-\mathrm{H} \cdots \mathrm{N}, \mathrm{C}-\mathrm{H} \cdots \mathrm{O}$, and $\mathrm{C}-\mathrm{H} \cdots \pi$ interactions $\left(\AA{ }^{\circ}\right)$.

\begin{tabular}{ccccc}
\hline $\mathbf{D}-\mathbf{H} \cdots \mathbf{A}$ & $\mathbf{d}(\mathbf{D}-\mathbf{H}) / \mathbf{A}$ & $\mathbf{d}(\mathbf{H} \mathbf{A} \mathbf{A}) / \mathbf{A}$ & $\mathbf{d}(\mathbf{D} \cdots \mathbf{A}) / \mathbf{A}$ & $\mathbf{D}-\mathbf{H} \cdots \mathbf{A})^{\circ}$ \\
\hline $\mathrm{C} 12-\mathrm{H} 12 \cdots \mathrm{N} 1{ }^{\mathrm{i}}$ & 0.95 & 2.56 & $3.505(3)$ & 172 \\
$\mathrm{C} 13-\mathrm{H} 13 \cdots \mathrm{O} 1{ }^{\mathrm{ii}}$ & 0.95 & 2.62 & 3.430 & 143 \\
$\mathrm{C} 8-\mathrm{H} 8 \mathrm{~B} \cdots \mathrm{C}_{g}{ }^{\mathrm{i}}$ & 0.99 & 2.61 & 3.574 & 165 \\
$\mathrm{C} 1-\mathrm{H} 1 \mathrm{~A} \cdots C_{g}$ & 0.98 & 2.95 & 3.931 & 175 \\
\hline Note that $C_{g}$ is the centroid of the benzene ring (C2-C7). Symmetry codes: (i) $-1+\mathrm{x}, \mathrm{y}, \mathrm{z} ;(\mathrm{ii}) 1-\mathrm{x},-1 / 2+\mathrm{y}$, \\
$1 / 2-\mathrm{z}$.
\end{tabular}

The interactions within the crystal of the benzoxazine (I) can be visualized by performing a Hirshfeld surface (HS) analysis [74,75] using Crystal Explorer 17.5 software (the University of Western Australia, Crawley, Australia) [76]. Hirshfeld surfaces for the benzoxazine (I) mapped over $d_{\text {norm }}$ in the range from -0.155 to +1.157 arbitrary units together with the shape-index-mapped Hirshfeld surfaces are displayed in Figure 3. As seen from Figure 3a, the bright red spots near $\mathrm{H} 12$ and N1 atoms correspond to the intermolecular $\mathrm{C} 12-\mathrm{H} 12 \cdots \mathrm{N} 1$ contact (green dash line), while the bright red spot near the H1A atom and the $C_{g}(\mathrm{C} 2-\mathrm{C} 7)$ centroid of the benzene ring represents the $\mathrm{C} 1-\mathrm{H} 1 \mathrm{~A} \cdots C_{g}$ interaction (orange circle). Moreover, the remarkable "pothole" on the shape-index-mapped Hirshfeld surface in between the H1A atom and the $C_{g}(\mathrm{C} 2-\mathrm{C} 7)$ centroid confirms the formation of the $\mathrm{C} 1-\mathrm{H} 1 \mathrm{~A} \cdots C_{g}$ interaction (orange circle, Figure $3 \mathrm{a}$ ). The red spots, as well as the notable "pothole" near $\mathrm{H} 8 \mathrm{~B}$ atom and $C_{\mathrm{g}}(\mathrm{C} 2-\mathrm{C} 7)$ centroid, support the presence of the $\mathrm{C} 8-\mathrm{H} 8 \mathrm{~B} \cdots \mathrm{C}_{g}(\mathrm{C}-\mathrm{H} \cdots \pi)$ contact (Figure $\left.3 \mathrm{~b}\right)$. The $\mathrm{C} 13-\mathrm{H} 13 \cdots \mathrm{O} 1$ contact can be illustrated by the red spots near the $\mathrm{H} 13$ and $\mathrm{O} 1$ atoms (yellow dash line, Figure 3c). As seen from the shape-index Hirshfeld surfaces, no $\pi \cdots \pi$ interactions were observed. The results agree with the analysis of interactions within the crystal structure discussed in the previous section.

To determine the contribution of each contact within the crystal packing quantitively, the two-dimensional fingerprint plot was calculated [77]. The full fingerprint plot and those delineated into $\mathrm{H} \cdots \mathrm{H}, \mathrm{H} \cdots \mathrm{C} / \mathrm{C} \cdots \mathrm{H}, \mathrm{H} \cdots \mathrm{O} / \mathrm{O} \cdots \mathrm{H}$, and $\mathrm{H} \cdots \mathrm{N} / \mathrm{N} \cdots \mathrm{H}$ interactions are illustrated in Figure 4a-e, respectively. Investigating the fingerprint plot shows that the significant interactions (together with their contributions) in the crystal structure of the benzoxazine (I) are $\mathrm{H} \cdots \mathrm{H}(58.5 \%), \mathrm{H} \cdots \mathrm{C} / \mathrm{C} \cdots \mathrm{H}(23.2 \%), \mathrm{H} \cdots \mathrm{O} / \mathrm{O} \cdots \mathrm{H}(15.6 \%)$, and $\mathrm{H} \cdots \mathrm{N} / \mathrm{N} \cdots \mathrm{H}(2.6 \%)$ with a total contribution of $\mathrm{H}$-related contacts of $99.9 \%$. Two most important contacts $(\mathrm{H} \cdots \mathrm{H}$ contacts and $\mathrm{H} \cdots \mathrm{C} / \mathrm{C} \cdots \mathrm{H}$ contacts) are characterized by a single spike at $d_{\mathrm{e}}+d_{\mathrm{i}} \simeq 2.2 \AA$ and a pair of peaks at $d_{\mathrm{e}}+d_{\mathrm{i}} \simeq 2.65 \AA$, respectively. These two contacts reveal that the molecules of the benzoxazine (I) are majorly held by van der Waals forces as well as $\mathrm{C}-\mathrm{H} \cdots \pi$ interactions. The $\mathrm{H} \cdots \mathrm{O} / \mathrm{O} \cdots \mathrm{H}$ contacts are viewed as a pair of sharp peaks at $d_{\mathrm{e}}+d_{\mathrm{i}} \simeq 2.5 \AA$, while the pair of sharp peaks for the $\mathrm{H} \cdots \mathrm{N} / \mathrm{N} \cdots \mathrm{H}$ contacts are located at $d_{\mathrm{e}}+d_{\mathrm{i}} \simeq 2.4 \AA$. The results confirm the presence of the $\mathrm{C}-\mathrm{H} \cdots \mathrm{N}$ interactions and the $\mathrm{C}-\mathrm{H} \cdots \mathrm{O}$ contacts with a relatively longer distance than $\mathrm{C}-\mathrm{H} \cdots \mathrm{N}$ interactions. The other contacts apart from the H-related contacts can be counted as a negligible effect on the crystal packing since their total contribution is only $0.1 \%$. 
(a) $\mathrm{C} 12-\mathrm{H} 12 \cdots \mathrm{N} 1$ and $\mathrm{C} 1-\mathrm{H} 1 \mathrm{~A} \cdots \mathrm{Cg}$ contacts
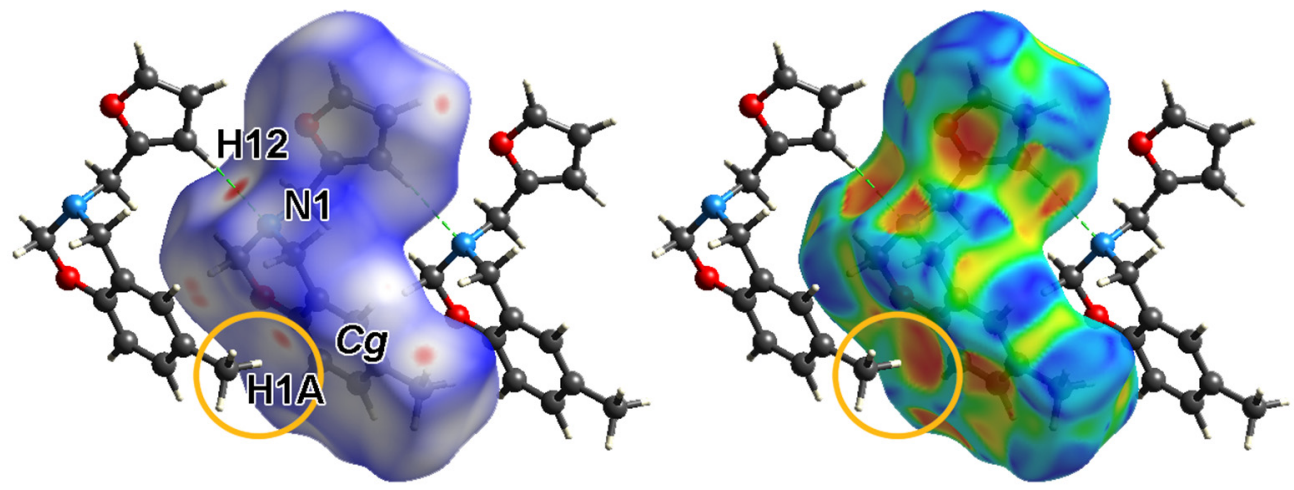

(b) C8-H8B $\cdots$ Cg contact
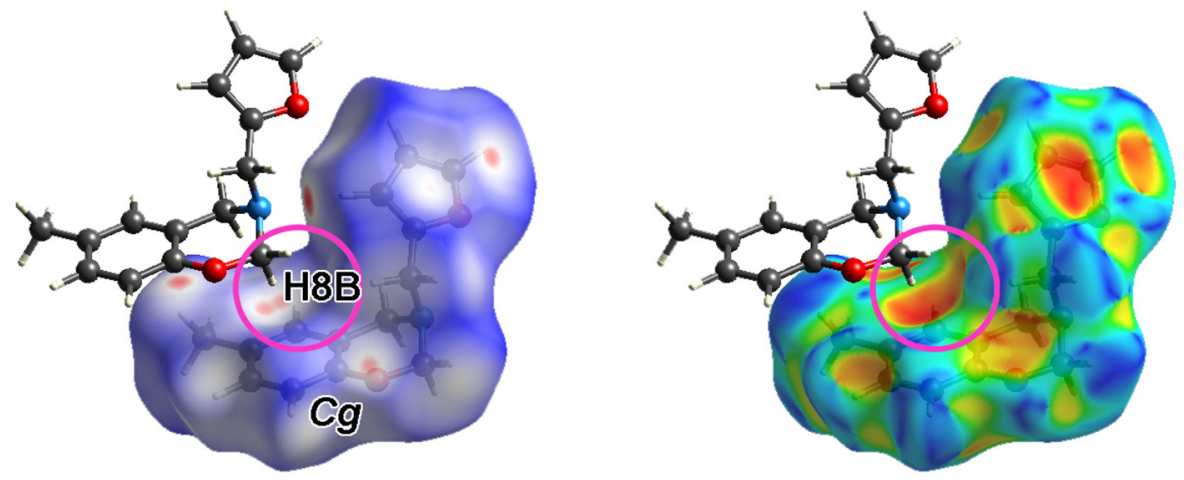

(c) $\mathrm{C} 13-\mathrm{H} 13 \cdots \mathrm{O} 1$ contact
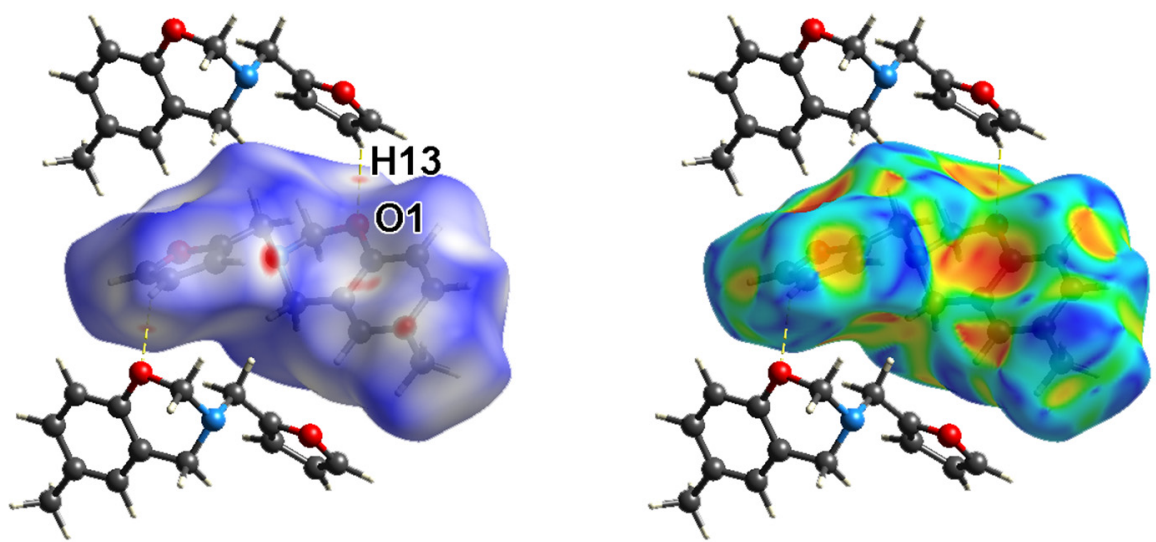

Figure 3. Views of the Hirshfeld surfaces for the benzoxazine (I) mapped over $d_{\text {norm }}$ in the range from -0.155 to +1.157 arbitrary units (left) and the shape-index property (right), each highlighting (a) the $\mathrm{C} 12-\mathrm{H} 12 \cdots \mathrm{N} 1$ (green dash line) and the $\mathrm{C} 1-\mathrm{H} 1 \mathrm{~A} \cdots \mathrm{C}_{g}$ (orange circle) contacts, (b) C $8-\mathrm{H} 8 \mathrm{~B} \cdots C_{g}$

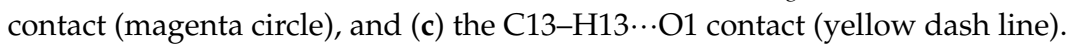




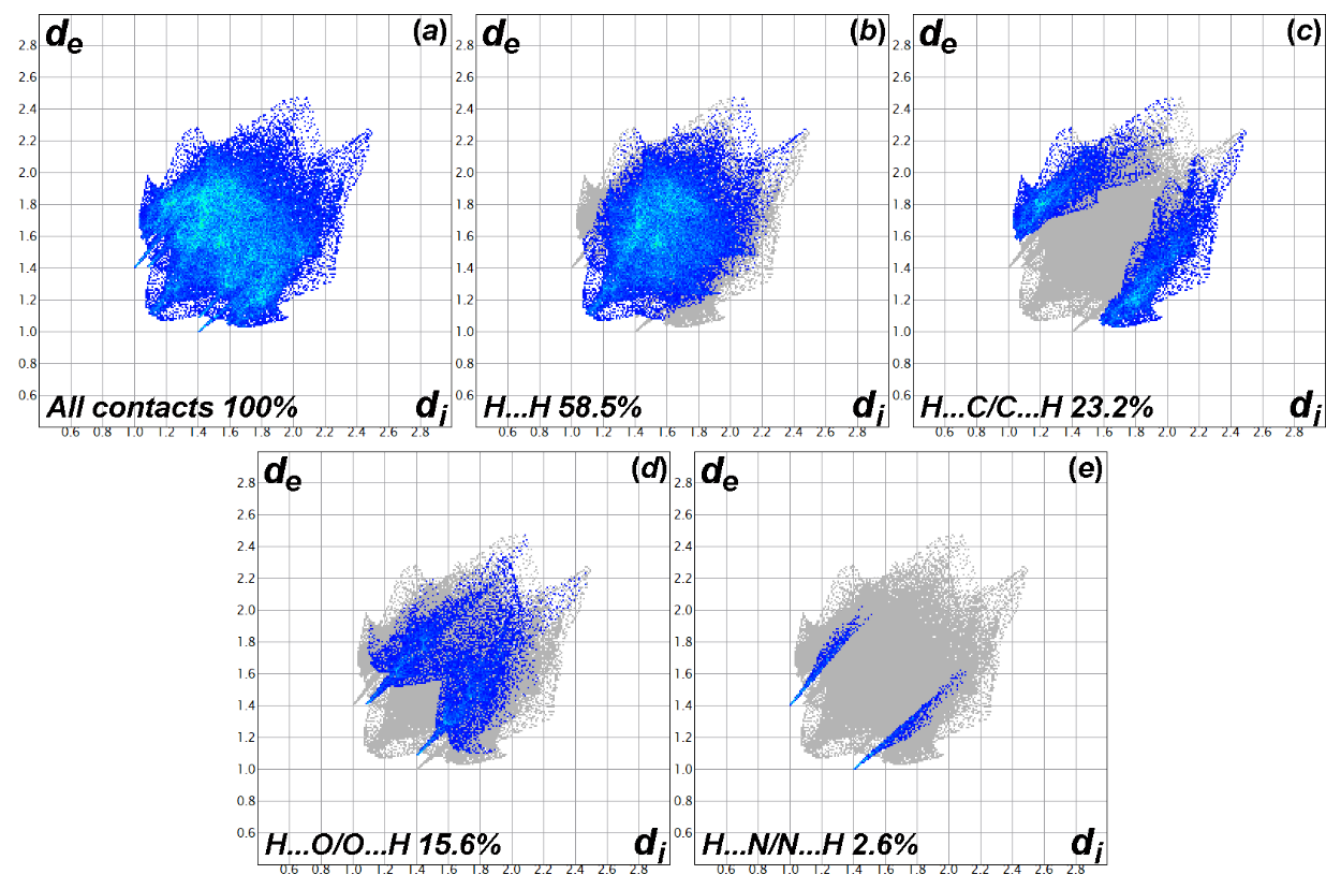

Figure 4. The full two-dimensional fingerprint plot from the corresponding, plotted over the $d_{\text {norm }}$ range from -0.155 to +1.157 arbitrary units for the benzoxazine (I), showing (a) all interactions and those delineated into (b) $\mathrm{H} \cdots \mathrm{H},(\mathbf{c}) \mathrm{H} \cdots \mathrm{C} / \mathrm{C} \cdots \mathrm{H}$, (d) $\mathrm{H} \cdots \mathrm{O} / \mathrm{O} \cdots \mathrm{H}$, and (e) $\mathrm{H} \cdots \mathrm{N} / \mathrm{N} \cdots \mathrm{H}$ interactions The $d_{\mathrm{i}}$ and $d_{\mathrm{e}}$ values are the closest internal and external distances (in $\AA$ ) from given points on the Hirshfeld surface.

\subsection{Photophysical Studies}

The absorption and emission spectra of the benzoxazine (I) were recorded in the solvents with various polarities (Figure 5). The relevant parameters were tabulated in Table 3. Herein, the benzoxazine (I) shows a broad absorption peak with various intensities in the range of $282-291 \mathrm{~nm}$ and a broad emission peak in the range of $297-313 \mathrm{~nm}$. The absorption and emission maxima were varied with different types of solvents depending on the polarity and proticity of the solvents. The differences in emission spectra were more pronounced compared to the ones in the absorption spectra, which suggests the higher polarity of the excited state than the ground state [78]. According to the limited studies on the luminescence properties of dihydrobenzoxazines, the fluorescence characteristics can be explained by comparing them to the other benzoxazole derivatives instead. The benzoxazine (I) showed an emission peak in most of the solvent studied in this work; however, no fluorescence was observed in the chloroform solution upon the excitation of the wavelength of $284 \mathrm{~nm}$. Generally, the maxima are blue-shifted in apolar solvents, while they are red-shifted in polar protic solvents [78]. However, there are some benzoxazole derivatives of which fluorescence signals are not very sensitive to the alteration of solvent polarities [79]. In our case, the solution of benzoxazine (I) in DMF exhibited the most blued-shift emission peak (the lowest Stoke shift) but the highest quantum yield. This result agrees well with the other derivatives reported in the literature [80], which could be ascribed to the intermolecular forces between benzoxazine (I) and DMF. Those forces include the strong interactions between the polar aprotic DMF solvent via the partially negative charge on the oxygen atom of the $\mathrm{C}=\mathrm{O}$ group and the partially positive charge on the hydrogen of the $-\mathrm{O}-\mathrm{CH}_{2}-\mathrm{N}-$ moiety in the benzoxazine (I). In the case of the solution in ACN, those intermolecular forces are weaker since the $\mathrm{N}$ atom of ACN is less electronegative than the $\mathrm{O}$ atom of DMF. 

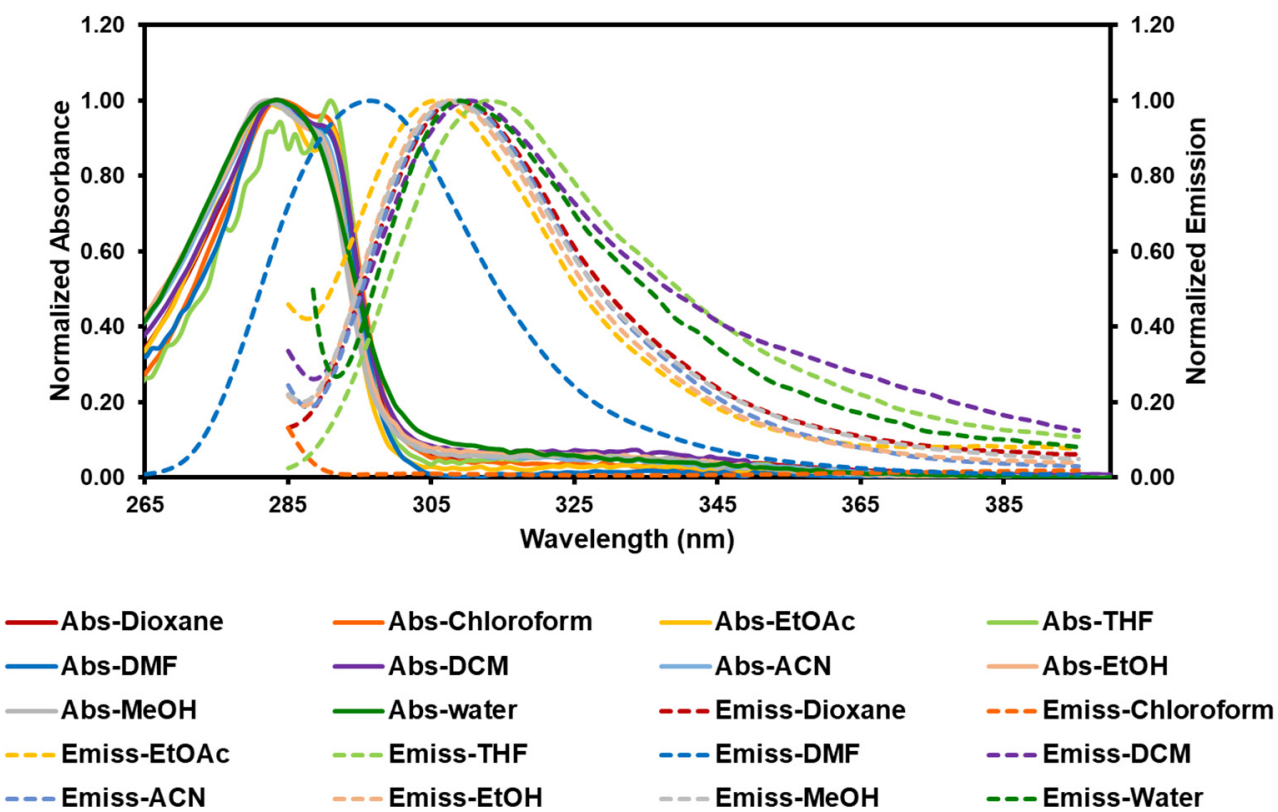

Figure 5. Normalized UV absorption and emission spectra of the benzoxazine (I) in various solvents.

Table 3. Photophysical properties of the benzoxazine (I) in various solvents.

\begin{tabular}{|c|c|c|c|c|c|}
\hline \multirow[t]{2}{*}{ Solvent } & \multicolumn{5}{|c|}{ Photophysical Properties } \\
\hline & $\begin{array}{c}\lambda_{\mathrm{abs}}^{\mathrm{a}} \\
(\mathrm{nm})\end{array}$ & $\begin{array}{c}\lambda_{\mathrm{em}} b \\
(\mathrm{~nm})\end{array}$ & $\begin{array}{l}\Delta U^{\mathrm{c}} \\
(\mathrm{nm})\end{array}$ & $\Phi_{\mathrm{f}}{ }^{d}$ & $\begin{array}{c}\mathrm{E}^{\mathrm{e}} \\
\left(\mathrm{M}^{-1} \mathrm{~cm}^{-1}\right)\end{array}$ \\
\hline Dioxane & 283 & 309 & 26 & 0.02 & $2.9 \times 10^{3}$ \\
\hline Chloroform & 284 & NF & NF & $\mathrm{NF}$ & $2.1 \times 10^{3}$ \\
\hline EtOAc & 282 & 306 & 24 & 0.03 & $1.9 \times 10^{3}$ \\
\hline $\mathrm{THF}$ & 291 & 313 & 22 & 0.03 & $1.9 \times 10^{3}$ \\
\hline DCM & 283 & 311 & 28 & 0.03 & $2.2 \times 10^{3}$ \\
\hline DMF & 283 & 297 & 14 & 0.24 & $2.5 \times 10^{3}$ \\
\hline $\mathrm{ACN}$ & 282 & 309 & 27 & 0.02 & $2.3 \times 10^{3}$ \\
\hline $\mathrm{EtOH}$ & 282 & 308 & 26 & 0.02 & $2.1 \times 10^{3}$ \\
\hline $\mathrm{MeOH}$ & 282 & 308 & 26 & 0.02 & $2.3 \times 10^{3}$ \\
\hline Water & 282 & 309 & 27 & 0.01 & $2.5 \times 10^{3}$ \\
\hline
\end{tabular}

\subsection{Computational Study}

To gain a better understanding of the absorption and emission spectra of the benzoxazine (I), quantum chemical calculations were performed. DFT and TD-DFT calculations at the B3LYP level of theory using the $6-311+G(d)$ basis set were computed to visualize the frontier molecular orbitals (FMOs) and to optimize the geometrical structures of ground states and excited states of the benzoxazine (I), respectively. The calculated absorption and emission characteristics of the benzoxazine (I) in the solvent with various polarities are listed in Table 4. In all solvent systems, the values of $\lambda_{\max }$ for UV-Vis absorption and fluorescence emission from TD-DFT calculations are around $0.3 \mathrm{eV}$ above the experimental values. It should be noted that TD-DFT is known to give overestimated excitation energies (up to $1 \mathrm{eV}$ ) [81]. Therefore, one is generally interested in the relative values rather than the absolute values. All absorption peaks were found to be involved in the electronic transition from the highest occupied molecular orbital (HOMO) to the lowest unoccupied molecular orbital (LUMO), $\mathrm{H} \rightarrow \mathrm{L}$, which can be assigned to a $\pi \rightarrow \pi^{*}$ transition. The proposed mechanism for the absorption and emission process of the benzoxazine (I) is depicted in Figure 6. The 
difference between absorption and emission is observed due to the vibrational relaxation causing the Stoke shift of about $30 \mathrm{~nm}$, which is in a good agreement with the experimental results. As we closely considered the FMO regarding the absorption process, it is worth noting that the HOMO of the ground state has a characteristic of the whole molecule as clearly seen from the presence of the electron orbitals located on almost every atom in the benzoxazine (I) molecule. On the other hand, the LUMO shows only the characteristic of the electronic structure belonging to the benzene group. For the emission process, the feature of LUMO resembles the one observed in the absorption process. However, the $\mathrm{HOMO}$ for the emission process is attributed to the electronic orbitals on the benzoxazine core structure, excluding the THF pedant group. Figure 7 displays the optimized structures of the ground and excited states at the PCM(acetonitrile)/B3LYP/6-311+G(d) and $\mathrm{PCM}$ (acetonitrile)/TD-B3LYP/6-311+G(d) levels of theory, respectively. The corresponding optimized structural parameters, e.g., bond lengths and dihedral angles, are tabulated in Table S2 and Table S3 (Supplementary Materials). It was seen that the bond lengths of the structures at the ground state and the excited state are remarkably similar. However, the dihedral angles involving in the benzoxazine core structure are significantly different. Specifically, the dihedral angles deviated from the planarity up to $10^{\circ}$. This might imply the reason why the characteristic of the LUMO is solely on the benzene moiety. Therefore, we can conclude that the fluorescence property of the benzoxazine (I) is the electronic transition from LUMO possessing the main characteristic of benzene moieties to the HOMO possessing the main feature of the benzoxazine ring.

Table 4. Calculated UV-Vis absorption and fluorescence emission for the benzoxazine (I) in different solvents.

\begin{tabular}{cccccccc}
\hline & & \multicolumn{3}{c}{ Absorption } & & Emission \\
\cline { 3 - 7 } Solvent & $\mathcal{E}$ & $\begin{array}{c}\text { Energy } \\
\text { nm (eV) }\end{array}$ & $\boldsymbol{f}^{\mathbf{a}}$ & $\begin{array}{c}\text { Electronic } \\
\text { Transition } \mathbf{b}\end{array}$ & $\begin{array}{c}\text { Energy } \\
\mathbf{n m}(\mathbf{e V})\end{array}$ & $\boldsymbol{f}^{\mathbf{a}}$ & $\begin{array}{c}\text { Electronic } \\
\text { Transition }\end{array}$ \\
\hline Dioxane & 2.210 & $262(4.73)$ & 0.0637 & $\mathrm{~S}_{0} \rightarrow \mathrm{S}_{1}(\mathrm{H} \rightarrow \mathrm{L})$ & $290(4.21)$ & 0.1013 & $\mathrm{~S}_{1} \rightarrow \mathrm{S}_{0}(\mathrm{~L} \rightarrow \mathrm{H})$ \\
Chloroform & 4.711 & $262(4.74)$ & 0.0648 & $\mathrm{~S}_{0} \rightarrow \mathrm{S}_{1}(\mathrm{H} \rightarrow \mathrm{L})$ & $291(4.26)$ & 0.1246 & $\mathrm{~S}_{1} \rightarrow \mathrm{S}_{0}(\mathrm{~L} \rightarrow \mathrm{H})$ \\
EtOAc & 5.987 & $261(4.74)$ & 0.0621 & $\mathrm{~S}_{0} \rightarrow \mathrm{S}_{1}(\mathrm{H} \rightarrow \mathrm{L})$ & $290(4.27)$ & 0.1304 & $\mathrm{~S}_{1} \rightarrow \mathrm{S}_{0}(\mathrm{~L} \rightarrow \mathrm{H})$ \\
THF & 7.426 & $261(4.74)$ & 0.0633 & $\mathrm{~S}_{0} \rightarrow \mathrm{S}_{1}(\mathrm{H} \rightarrow \mathrm{L})$ & $291(4.26)$ & 0.1349 & $\mathrm{~S}_{1} \rightarrow \mathrm{S}_{0}(\mathrm{~L} \rightarrow \mathrm{H})$ \\
DCM & 8.930 & $261(4.74)$ & 0.0641 & $\mathrm{~S}_{0} \rightarrow \mathrm{S}_{1}(\mathrm{H} \rightarrow \mathrm{L})$ & $291(4.26)$ & 0.1382 & $\mathrm{~S}_{1} \rightarrow \mathrm{S}_{0}(\mathrm{~L} \rightarrow \mathrm{H})$ \\
DMF & 37.219 & $261(4.75)$ & 0.0643 & $\mathrm{~S}_{0} \rightarrow \mathrm{S}_{1}(\mathrm{H} \rightarrow \mathrm{L})$ & $291(4.26)$ & 0.1525 & $\mathrm{~S}_{1} \rightarrow \mathrm{S}_{0}(\mathrm{~L} \rightarrow \mathrm{H})$ \\
ACN & 35.688 & $261(4.76)$ & 0.0610 & $\mathrm{~S}_{0} \rightarrow \mathrm{S}_{1}(\mathrm{H} \rightarrow \mathrm{L})$ & $291(4.27)$ & 0.1523 & $\mathrm{~S}_{1} \rightarrow \mathrm{S}_{0}(\mathrm{~L} \rightarrow \mathrm{H})$ \\
EtOH & 24.852 & $261(4.75)$ & 0.0616 & $\mathrm{~S}_{0} \rightarrow \mathrm{S}_{1}(\mathrm{H} \rightarrow \mathrm{L})$ & $291(4.27)$ & 0.1501 & $\mathrm{~S}_{1} \rightarrow \mathrm{S}_{0}(\mathrm{~L} \rightarrow \mathrm{H})$ \\
MeOH & 32.613 & $261(4.76)$ & 0.0603 & $\mathrm{~S}_{0} \rightarrow \mathrm{S}_{1}(\mathrm{H} \rightarrow \mathrm{L})$ & $290(4.27)$ & 0.1518 & $\mathrm{~S}_{1} \rightarrow \mathrm{S}_{0}(\mathrm{~L} \rightarrow \mathrm{H})$ \\
Water & 78.355 & $261(4.76)$ & 0.0605 & $\mathrm{~S}_{0} \rightarrow \mathrm{S}_{1}(\mathrm{H} \rightarrow \mathrm{L})$ & $291(4.27)$ & 0.1552 & $\mathrm{~S}_{1} \rightarrow \mathrm{S}_{0}(\mathrm{~L} \rightarrow \mathrm{H})$ \\
\hline
\end{tabular}

a Oscillator strength. ${ }^{\mathrm{b}} \mathrm{H}, \mathrm{HOMO}$ (highest occupied molecular orbital) and L, LUMO (lowest unoccupied molecular orbital). 


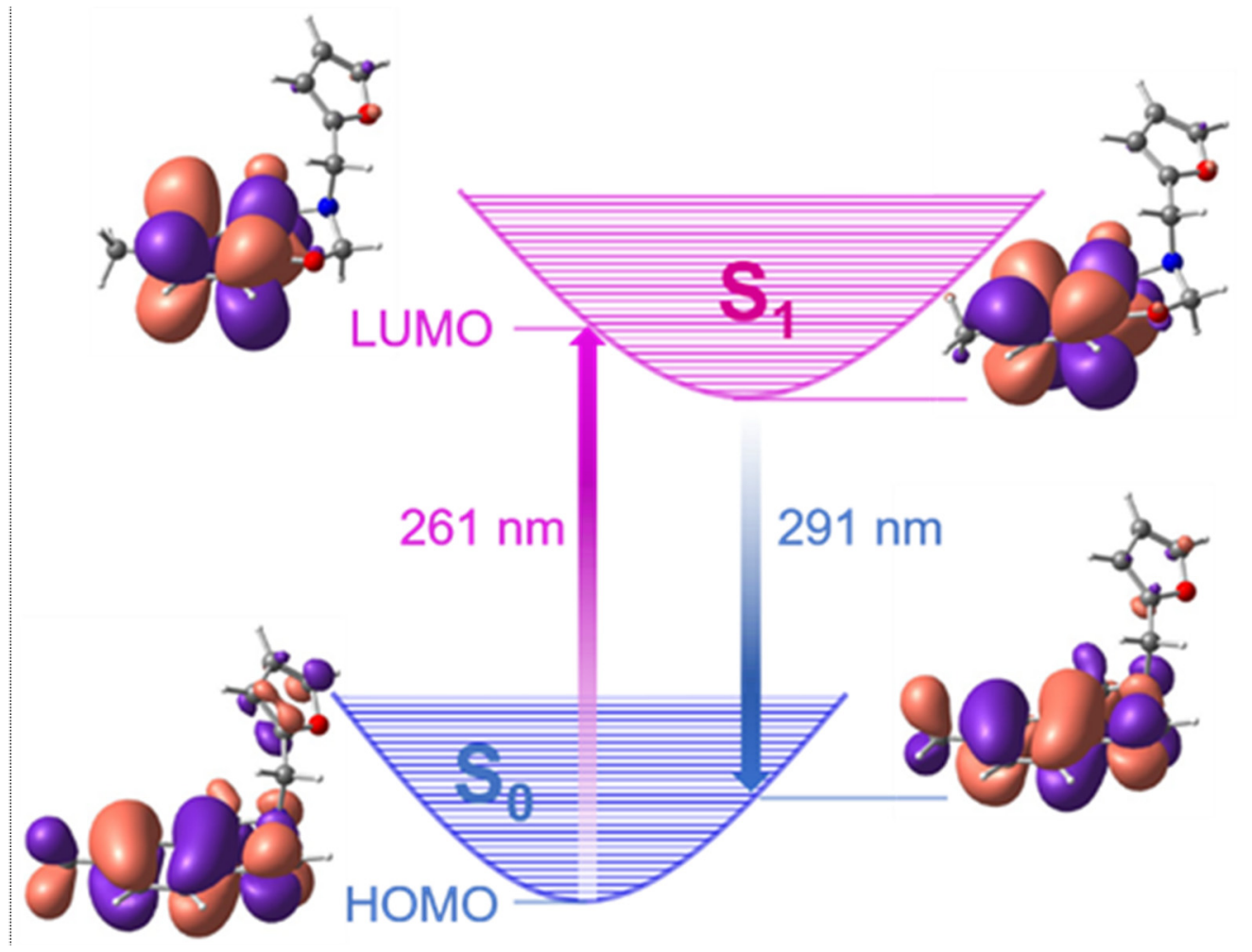

Figure 6. Schematic diagram of electronic transition processes of the benzoxazine (I) in acetonitrile.
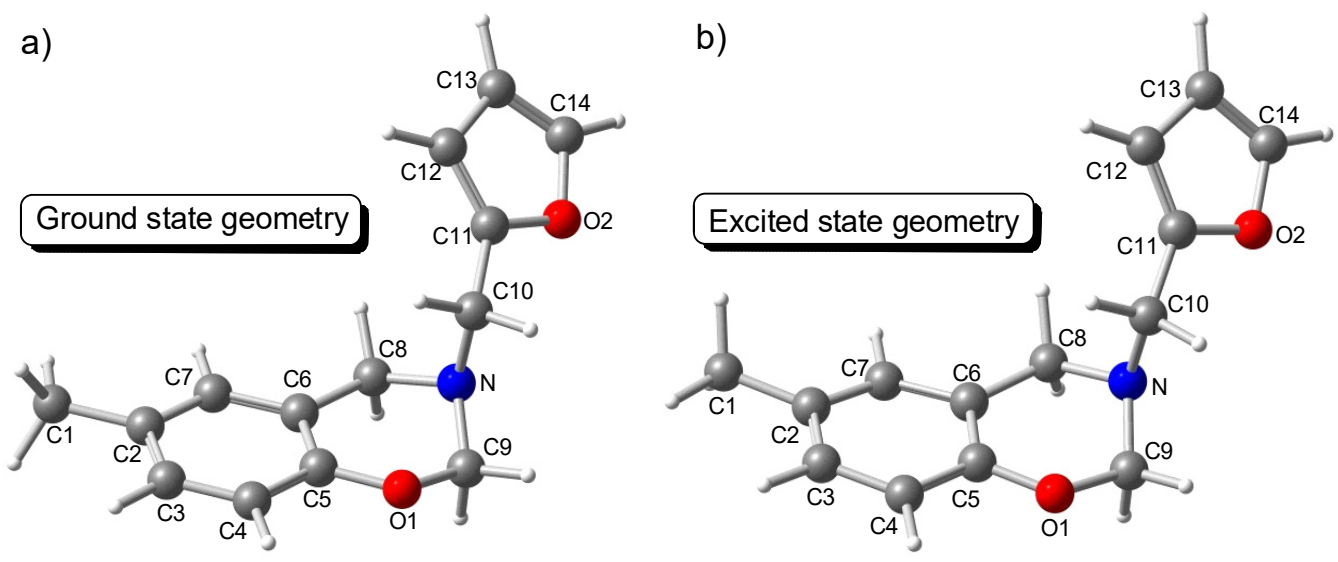

Figure 7. Optimized (a) ground state and (b) excited state geometries of the benzoxazine (I) at the PCM(acetonitrile)/B3LYP/6-311+G(d) and PCM(acetonitrile)/TD-B3LYP/6-311+G(d) levels of theory, respectively.

\section{Conclusions}

This work reported the successful synthesis of the novel benzoxazine monomer-the so-called 3-(furan-2-ylmethyl)-6-methyl-3,4-dihydro-2H-benzo[e][1,3]oxazine, otherwise known as benzoxazine (I) - from a one-pot Mannich reaction, and the investigation of its photophysical properties was also carried out. The X-ray crystallography disclosed that the benzoxazine moiety tried to arrange its atoms as planar as possible by expanding the $\mathrm{C}-\mathrm{O}-\mathrm{C}$ and $\mathrm{N}-\mathrm{C}-\mathrm{O}$ bonds. The $\mathrm{C}-\mathrm{N}-\mathrm{C}$ bonds were not as deviated as the $\mathrm{C}-\mathrm{O}-\mathrm{C}$ and $\mathrm{N}-\mathrm{C}-\mathrm{O}$ bonds. For the $\mathrm{C}-\mathrm{H} \cdots \mathrm{N}$ interactions, one of the furan hydrogens and an amine nitrogen atom joined between the benzoxazine (I) molecules, creating a $C_{1}{ }^{1}(5)$ molecule chain. Two types of $\mathrm{C}-\mathrm{H} \cdots \pi$ short were observed on the opposite sides of the benzene ring. The first $\mathrm{C}-\mathrm{H} \cdots \pi$ contact was formed between the centroid of the benzene ring $\left(C_{g}\right)$ and the methylene group of the $\mathrm{O}-\mathrm{CH}_{2}-\mathrm{N}$ of the oxazine ring. The second $\mathrm{C}-\mathrm{H} \cdots \pi$ contact was 
set up from the centroid of the benzene ring and one of the $\mathrm{H}$ atoms in the tetrahydrofuran group. Apart from the $\mathrm{C}-\mathrm{H} \cdots \mathrm{N}$ and $\mathrm{C}-\mathrm{H} \cdots \pi$ interactions, the $\mathrm{C}-\mathrm{H} \cdots \mathrm{O}$ interaction was also established between different molecules of the benzoxazine (I) related by a $2{ }_{1}$-screw axis, resulting in a $C_{1}^{1}(8)$ supramolecular chain. The absorption and emission spectra of the benzoxazine (I) in the different solvents were collected and compared with DFT calculated results, showing a broad absorption peak around 282-291 nm and a broad emission peak around 297-313 nm. A significant blued shift was observed in DMF solution because of the unique intermolecular forces between benzoxazine (I) and DMF. The absorption peak was attributed to the $\mathrm{HOMO} \rightarrow \mathrm{LUMO}$ transition, where the $\mathrm{HOMO}$ had a characteristic of the whole molecule. On the contrary, the LUMO has a feature of the benzene ring only. In other word, the fluorescence phenomenon was occurred via the electronic transition from LUMO with a main contribution from benzene characteristics toward HOMO, possessing whole benzoxazine (I) contribution.

Supplementary Materials: The following are available online at https:/ /www.mdpi.com/article/10 .3390 / cryst11050568/s1. Figure S1: ${ }^{1} \mathrm{H}-\mathrm{NMR}$ spectrum of the benzoxazine (I). Figure S2: ${ }^{13} \mathrm{C}-\mathrm{NMR}$ spectrum of the benzoxazine (I). Figure S3: ESI-MS spectrum of the benzoxazine (I). Figure S4: Raman spectrum of the benzoxazine (I). Figure S5: FT-IR spectrum of the benzoxazine (I). Figure S6: Comparing powder X-ray diffraction pattern (PXRD) of the benzoxazine (I), 3-[(furan-2-yl)methyl]6-methyl-3,4-dihydro-2H-1,3-benzoxazine, measured by using a monochromatic synchrotron $\mathrm{X}$ ray with an energy of $12 \mathrm{keV}$ (wavelength $1.0332 \AA$ ) plotted in blue color with respect to the simulated PXRD from cif file collected from single crystal X-ray crystallography (black plot). Figure S7: Superimposition of the X-ray (with atom labels) and gas-phase optimized (white color) structures of the benzoxazine (I). Table S1: Selected bond lengths, bond angles, and dihedral angles of the optimized ground state structures of the benzoxazine (I) in gas phase compared with that in solid crystals. Table S2: Selected bond lengths and dihedral angles of the optimized ground state (GS) and excited state (ES) structures of the benzoxazine (I) in different solvents (dioxane, chloroform, EtOAc, THF and DCM). Table S3: Selected bond lengths and dihedral angles of the optimized ground state (GS) and excited state (ES) structures of the benzoxazine (I) in different solvents (EtOH, MeOH, ACN, DMF and water). Reported cartesian coordinates of the optimized structures of the benzoxazine (I) at ground state and excited state.

Author Contributions: Conceptualization, W.W.; data curation, W.W.; formal analysis, W.W.; funding acquisition, W.W.; investigation, W.W., Y.H., S.W., K.C., P.P. and T.N.; methodology, W.W.; project administration, W.W.; resources, W.W.; software, T.N.; supervision, W.W.; validation, W.W.; visualization, W.W.; writing-original draft, W.W. and Y.H.; Writing-review \& editing, W.W., S.W., K.C. and P.K. All authors have read and agreed to the published version of the manuscript.

Funding: This research received no external funding.

Institutional Review Board Statement: Not applicable.

Informed Consent Statement: Not applicable.

Data Availability Statement: The data presented in this study are available within the article and in Supplementary Material.

Acknowledgments: The Department of Materials Engineering, Faculty of Engineering, Kasetsart University, National Nanotechnology Center, National Science and Technology Development Agency, and the School of Chemistry, Institute of Science, Suranaree University of Technology are acknowledged for the support of the facilities. We acknowledge the Synchrotron Light Research Institute (Public Organization), SLRI, Thailand, for the provision of beamtime for XRD at BL1.1W. All research staffs of BL1.1W are acknowledged for their assistance during the experiment. Finally, the authors would like to thank Apirat Laobuthee for his support on certain facilities and equipment.

Conflicts of Interest: The authors declare no conflict of interest. 


\section{References}

1. Ishida, H.; Agag, T. Handbook of Benzoxazine Resins; Elsevier: Amsterdam, The Netherlands, 2011.

2. Zhang, K.; Froimowicz, P.; Ishida, H. Development of new generation benzoxazine thermosets based on smart ortho-benzoxazine chemistry. Adv. Emerg. Polybenzoxazine Sci. Technol. 2017, 35-64. [CrossRef]

3. Chernykh, A.; Agag, T.; Ishida, H. Novel benzoxazine monomer containing diacetylene linkage: An approach to benzoxazine thermosets with low polymerization temperature without added initiators or catalysts. Polymer 2009, 50, 3153-3157. [CrossRef]

4. Vaithilingam, S.; Jayanthi, K.P.; Muthukaruppan, A. Synthesis and characterization of cardanol based fluorescent composite for optoelectronic and antimicrobial applications. Polymer 2017, 108, 449-461. [CrossRef]

5. Yen, H.-J.; Liou, G.-S. Design and preparation of triphenylamine-based polymeric materials towards emergent optoelectronic applications. Prog. Polym. Sci. 2019, 89, 250-287. [CrossRef]

6. Alper-Hayta, S.; Aki-Sener, E.; Tekiner-Gulbas, B.; Yildiz, I.; Temiz-Arpaci, O.; Yalcin, I.; Altanlar, N. Synthesis, antimicrobial activity and QSARs of new benzoxazine-3-ones. Eur. J. Med. Chem. 2006, 41, 1398-1404. [CrossRef]

7. Periyasamy, T.; Asrafali, S.; Shanmugam, M.; Kim, S.-C. Development of sustainable and antimicrobial film based on polybenzoxazine and cellulose. Int. J. Biol. Macromol. 2021, 170, 664-673. [CrossRef] [PubMed]

8. Yadav, N.; Monisha, M.; Niranjan, R.; Dubey, A.; Patil, S.; Priyadarshini, R.; Lochab, B. Antibacterial performance of fully biobased chitosan-grafted-polybenzoxazine films: Elaboration and properties of released material. Carbohydr. Polym. 2021, $254,117296$. [CrossRef]

9. Thirukumaran, P.; Manoharan, R.K.; Parveen, A.S.; Atchudan, R.; Kim, S.-C. Sustainability and antimicrobial assessments of apigenin based polybenzoxazine film. Polymer 2019, 172, 100-109. [CrossRef]

10. Huang, S.; Gu, J.; Ye, J.; Fang, B.; Wan, S.; Wang, C.; Ashraf, U.; Li, Q.; Wang, X.; Shao, L.; et al. Benzoxazine monomer derived carbon dots as a broad-spectrum agent to block viral infectivity. J. Colloid Interface Sci. 2019, 542, 198-206. [CrossRef]

11. Gupta, N.; Sharma, S.; Raina, A.; Dangroo, N.A.; Bhushan, S.; Sangwan, P.L. Synthesis and anti-proliferative evaluation of novel 3,4-dihydro-2H-1,3-oxazine derivatives of bakuchiol. RSC Adv. 2016, 6, 106150-106159. [CrossRef]

12. Mbaba, M.; Dingle, L.M.K.; Cash, D.; Mare, J.-A.D.L.; Laming, D.; Taylor, D.; Hoppe, H.C.; Edkins, A.L.; Khanye, S.D. Repurposing a polymer precursor: Synthesis and in vitro medicinal potential of ferrocenyl 1,3-benzoxazine derivatives. Eur. J. Med. Chem. 2020, 187, 111924. [CrossRef] [PubMed]

13. Carramiñana, V.; Ochoa de Retana, A.M.; de los Santos, J.M.; Palacios, F. First synthesis of merged hybrids phosphorylated azirino[2,1-b]benzo[e][1,3]oxazine derivatives as anticancer agents. Eur. J. Med. Chem. 2020, 185, 111771. [CrossRef] [PubMed]

14. Xu, Y.; Li, P.; Li, L.; Dai, J.; Ran, Q.; Gu, Y. Thermal degradation mechanism of a cured acetylene/aldehyde functional benzoxazine with high thermal stability. Polym. Degrad. Stab. 2020, 171, 109041. [CrossRef]

15. Liao, Y.-T.; Lin, Y.-C.; Kuo, S.-W. Highly thermally stable, transparent, and flexible polybenzoxazine nanocomposites by combination of double-decker-shaped polyhedral silsesquioxanes and polydimethylsiloxane. Macromolecules 2017, 50, 5739-5747. [CrossRef]

16. Ran, Q.-C.; Zhang, D.-X.; Zhu, R.-Q.; Gu, Y. The structural transformation during polymerization of benzoxazine $/ \mathrm{FeCl}_{3}$ and the effect on the thermal stability. Polymer 2012, 53, 4119-4127. [CrossRef]

17. Zhang, K.; Liu, J.; Ohashi, S.; Liu, X.; Han, Z.; Ishida, H. Synthesis of high thermal stability polybenzoxazoles via ortho-imidefunctional benzoxazine monomers. J. Polym. Sci. Part A Polym. Chem. 2015, 53, 1330-1338. [CrossRef]

18. El-Mahdy, A.F.M.; Kuo, S.W. Direct synthesis of poly(benzoxazine imide) from an ortho-benzoxazine: Its thermal conversion to highly cross-linked polybenzoxazole and blending with poly(4-vinylphenol). Polym. Chem. 2018, 9, 1815-1826. [CrossRef]

19. Pei, L.; Zhao, S.; Li, H.; Zhang, X.; Fan, X.; Wang, W.; Zhang, C.; Zhao, G.; Wang, Z. Preparation of low temperature cure polybenzoxazine coating with enhanced thermal stability and mechanical properties by combustion synthesis approach. Polymer 2021, 220, 123573. [CrossRef]

20. Chen, C.-H.; Lin, C.-H.; Hon, J.-M.; Wang, M.-W.; Juang, T.-Y. First halogen and phosphorus-free, flame-retardant benzoxazine thermosets derived from main-chain type bishydroxydeoxybenzoin-based benzoxazine polymers. Polymer 2018, $154,35-41$. [CrossRef]

21. Zhang, K.; Han, L.; Froimowicz, P.; Ishida, H. A smart latent catalyst containing otrifluoroacetamide functional benzoxazine: Precursor for low temperature formation of very high performance polybenzoxazole with low dielectric constant and high thermal stability. Macromolecules 2017, 50, 6552-6560. [CrossRef]

22. Wu, J.; Xi, Y.; McCandless, G.T.; Xie, Y.; Menon, R.; Patel, Y.; Yang, D.J.; Iacono, S.T.; Novak, B.M. Synthesis and characterization of partially fluorinated polybenzoxazine resins utilizing octafluorocyclopentene as a versatile building block. Macromolecules 2015, 48, 6087-6095. [CrossRef]

23. Chen, K.-C.; Li, H.-T.; Huang, S.-C.; Chen, W.-B.; Sun, K.-W.; Chang, F.-C. Synthesis and performance enhancement of novel polybenzoxazines with low surface free energy. Polym. Int. 2011, 60, 1089-1096. [CrossRef]

24. Zhang, K.; Yu, X.; Kuo, S.W. Outstanding dielectric and thermal properties of main chain-type poly(benzoxazine-co-imide-cosiloxane)-based cross-linked networks. Polym. Chem. 2019, 10, 2387-2396. [CrossRef]

25. Cao, Y.; Chen, C.; Lu, X.; Xu, D.; Huang, J.; Xin, Z. Bio-based polybenzoxazine superhydrophobic coating with active corrosion resistance for carbon steel protection. Surf. Coat. Technol. 2021, 405, 126569. [CrossRef]

26. Chen, C.; Cao, Y.; Lu, X.; Li, X.; Yao, H.; Xin, Z. Copolymer of eugenol-based and pyrogallol-based benzoxazines: Low curing temperature and enhanced corrosion resistance. Colloids Surf. A Physicochem. Eng. 2021, 609, 125605. [CrossRef] 
27. Zachariah, S.; Liu, Y.-L. Nanocomposites of polybenzoxazine-functionalized multiwalled carbon nanotubes and polybenzoxazine for anti-corrosion application. Compos. Sci. Technol. 2020, 194, 108169. [CrossRef]

28. Aly, K.I.; Mohamed, M.G.; Younis, O.; Mahross, M.H.; Abdel-Hakim, M.; Sayed, M.M. Salicylaldehyde azine-functionalized polybenzoxazine: Synthesis, characterization, and its nanocomposites as coatings for inhibiting the mild steel corrosion. Prog. Org. Coat. 2020, 138, 105385. [CrossRef]

29. Mohamed, M.G.; Kuo, S.W.; Mahdy, A.; Ghayd, I.M.; Aly, K.I. Bisbenzylidene cyclopentanone and cyclohexanone-functionalized polybenzoxazine nanocomposites: Synthesis, characterization, and use for corrosion protection on mild steel. Mater. Today Commun. 2020, 25, 101418. [CrossRef]

30. Xu, D.; Lou, C.; Huang, J.; Lu, X.; Xin, Z.; Zhou, C. Effect of inhibitor-loaded halloysite nanotubes on active corrosion protection of polybenzoxazine coatings on mild steel. Prog. Org. Coat. 2019, 134, 126-133. [CrossRef]

31. Voiciuk, V.; Redeckas, K.; Martynaitis, V.; Steponavičiute, R.; Šačkus, A.; Vengris, M. Improving the photochromic properties of indolo[2,1-b][1,3]benzoxazines with phenylic substituents. J. Photochem. Photobiol. A Chem. 2014, 278, 60-68. [CrossRef]

32. Wang, Y.; Niu, H.; Lu, Q.; Zhang, W.; Qiao, X.; Niu, H.; Zhang, Y.; Wang, W. From aerospace to screen: Multifunctional poly(benzoxazine)s based on different triarylamines for electrochromic, explosive detection and resistance memory devices. Spectrochim. Acta A Mol. Biomol. Spectrosc. 2020, 225, 117524. [CrossRef] [PubMed]

33. Wattanathana, W.; Nonthaglin, S.; Veranitisagul, C.; Koonsaeng, N.; Laobuthee, A. Crystal structure and novel solid-state fluorescence behavior of the model benzoxazine monomer: 3,4-Dihydro-3,6-dimethyl-1,3,2H-benzoxazine. J. Mol. Struct. 2014, 1074, 118-125. [CrossRef]

34. Calò, E.; Maffezzoli, A.; Mele, G.; Martina, F.; Mazzetto, S.E.; Tarzia, A.; Stifani, C. Synthesis of a novel cardanol-based benzoxazine monomer and environmentally sustainable production of polymers and bio-composites. Green Chem. 2007, 9, 754-775. [CrossRef]

35. Zhang, K.; Han, M.; Liu, Y.; Froimowicz, P. Design and synthesis of bio-based high-performance trioxazine benzoxazine resin via natural renewable resources. ACS Sustain. Chem. Eng. 2019, 7, 9399-9407. [CrossRef]

36. Thirukumaran, P.; Parveen, A.S.; Sarojadevi, M. Synthesis and copolymerization of fully biobased benzoxazines from renewable resources. ACS Sustain. Chem. Eng. 2014, 2, 2790-2801. [CrossRef]

37. Wang, C.; Sun, J.; Liu, X.; Sudo, A.; Endo, T. Synthesis and copolymerization of fully bio-based benzoxazines from guaiacol, furfurylamine and stearylamine. Green Chem. 2012, 14, 2799-2806. [CrossRef]

38. Teng, N.; Yang, S.; Dai, J.; Wang, S.; Zhao, J.; Zhu, J.; Liu, X. Making benzoxazine greener and stronger: Renewable resource, microwave irradiation, green solvent, and excellent thermal properties. ACS Sustain. Chem. Eng. 2019, 7, 8715-8723. [CrossRef]

39. Kiskan, B.; Yagci, Y. Thermally curable benzoxazine monomer with a photodimerizable coumarin group. J. Polym. Sci. Part A Polym. Chem. 2007, 45, 1670-1676. [CrossRef]

40. Froimowicz, P.; Arza, C.R.; Han, L.; Ishida, H. Smart, sustainable, and ecofriendly chemical design of fully bio-based thermally stable thermosets based on benzoxazine chemistry. ChemSusChem 2016, 1921-1928. [CrossRef]

41. Peng, Y.; Dai, J.; Liu, Y.; Cao, L.; Zhu, J.; Liu, X. Bio-based polybenzoxazine modified melamine sponges for selective absorption of organic solvent in water. Adv. Sustain. Syst. 2019, 3, 1800126. [CrossRef]

42. Liu, X.; Zhang, R.; Li, T.; Zhu, P.; Zhuang, Q. Novel fully biobased benzoxazines from rosin: Synthesis and properties. ACS Sustain. Chem. Eng. 2017, 5, 10682-10692. [CrossRef]

43. Yang, R.; Han, M.; Hao, B.; Zhang, K. Biobased high-performance tri-furan functional bis-benzoxazine resin derived from renewable guaiacol, furfural and furfurylamine. Eur. Polym. J. 2020, 131, 109706. [CrossRef]

44. Dai, J.; Teng, N.; Peng, Y.; Liu, Y.; Cao, L.; Zhu, J.; Liu, X. Biobased benzoxazine derived from daidzein and furfurylamine: Microwave-Assisted synthesis and thermal properties investigation. ChemSusChem 2018, 11, 3175-3183. [CrossRef] [PubMed]

45. Teong, S.P.; Yi, G.; Zhang, Y. Hydroxymethylfurfural production from bioresources: Past, present and future. Green Chem. 2014, 16, 2015-2026. [CrossRef]

46. Chirachanchai, S.; Laobuthee, A.; Phongtamrug, S. Self termination of ring opening reaction of $p$-substituted phenol-based benzoxazines: An obstructive effect via intramolecular hydrogen bond. J. Heterocycl. Chem. 2009, 46, 714-721. [CrossRef]

47. Kaewvilai, A.; Rujitanapanich, S.; Wattanathana, W.; Veranitisagul, C.; Suramitr, S.; Koonsaeng, N.; Laobuthee, A. The effect of alkali and $\mathrm{Ce}(\mathrm{III})$ ions on the response properties of benzoxazine supramolecules prepared via molecular assembly. Molecules 2012, 17, 511-526. [CrossRef]

48. SAINT Version 8.34A 2013; Bruker AXS: Madison, WI, USA, 2013.

49. Sheldrick, G.M. SADABS; University of Göttingen: Göttingen, Germany, 1996.

50. Dolomanov, O.V.; Bourhis, L.J.; Gildea, R.J.; Howard, J.A.K.; Puschmann, H. OLEX2: A complete structure solution, refinement and analysis program. J. Appl. Crystallogr. 2009, 42, 339-341. [CrossRef]

51. Sheldrick, G.M. SHELXT-Integrating space group determination and structure solution. Acta Cryst. Crystallogr. A 2014, 70, C1437. [CrossRef]

52. Sheldrick, G.M. Crystal structure refinement with SHELXL. Acta Cryst. 2015, C71, 3-8.

53. Macrae, C.F.; Edgington, P.R.; McCabe, P.; Pidcock, E.; Shields, G.P.; Taylor, R.; Towler, M.; van de Streek, J. Mercury: Visualization and analysis of crystal structures. J. Appl. Crystallogr. 2006, 39, 453-457. [CrossRef]

54. Frisch, M.J.; Trucks, G.W.; Schlegel, H.B.; Scuseria, G.E.; Robb, M.A.; Cheeseman, J.R.; Scalmani, G.; Barone, V.; Mennucci, B.; Petersson, G.A.; et al. Gaussian 09, Revision B. 01; Gaussian Inc.: Wallingford, CT, USA, 2010.

55. Becke, A.D. Density-Functional thermochemistry. III. The role of exact exchange. J. Chem. Phys. 1993, 98, 5648-5652. [CrossRef] 
56. Raghavachari, K. Perspective on "Density functional thermochemistry. III. The role of exact exchange". Theor. Chem. Acc. 2000, 103, 361-363. [CrossRef]

57. Miehlich, B.; Savin, A.; Stoll, H.; Preuss, H. Results obtained with the correlation energy density functionals of becke and Lee, Yang and Parr. Chem. Phys. Lett. 1989, 157, 200-206. [CrossRef]

58. Lee, C.; Yang, W.; Parr, R.G. Development of the Colle-Salvetti correlation-energy formula into a functional of the electron density. Phys. Rev. B 1988, 37, 785-789. [CrossRef] [PubMed]

59. Krishnan, R.; Binkley, J.S.; Seeger, R.; Pople, J.A. Self-consistent molecular orbital methods. XX. A basis set for correlated wave functions. J. Chem. Phys. 1980, 72, 650-654. [CrossRef]

60. Clark, T.; Chandrasekhar, J.; Spitznagel, G.W.; Schleyer, P.V.R. Efficient diffuse function-augmented basis sets for anion calculations. III. The 3-21+G basis set for first-row elements, Li-F. J. Comp. Chem. 1983, 4, 294-301. [CrossRef]

61. Cossi, M.; Barone, V. Analytical second derivatives of the free energy in solution by polarizable continuum models. J. Chem. Phys. 1998, 109, 6246-6254. [CrossRef]

62. Rivera, A.; Camacho, J.; Ríos-Motta, J.; Kučeraková, M.; Dušek, M. 3,3'-(Ethane-1,2-diyl)bis(6-methoxy-3,4-dihydro-2H-1,3benzoxazine) monohydrate. Acta Cryst. 2012, E68, o2734. [CrossRef] [PubMed]

63. Arendt-Pindel, A.; Marszałek-Harych, A.; Gẹbarowska, E.; Gẹbarowski, T.; Jẹdrzkiewicz, D.; Plaskowska, E.; Zalewski, D.; Gulia, N.; Szafert, S.ł.; Ejfler, J. Design and functionalization of bioactive benzoxazines. An unexpected ortho-substitution effect. New J. Chem. 2019, 43, 12042-12053. [CrossRef]

64. Cremer, D.; Pople, J.A. A general definition of ring puckering coordinates. J. Am. Chem. Soc. 1975, 97, 1354-1358. [CrossRef]

65. Liu, X.; Gu, Y. Effects of molecular structure parameters on ring-opening reaction of benzoxazines. Sci. China B Chem. 2001, 44 , 552-560. [CrossRef]

66. Chen, X.-L.; Wu, M.-H. 3-Benzyl-6-methyl-3,4-dihydro-2H-1,3-benzoxazine. Acta Crystallogr. Sect. E 2007, 63, o3684. [CrossRef]

67. Andrews, P.R.; Cody, V.; Gulbis, J.M.; Iskander, M.N.; Jeffrey, A.I.; Mackay, M.F.; Di paola, C.; Sadek, M. Structure and conformations of GABA-transaminase inhibitors. II transition state analogues. Aust. J. Chem. 1985, 39, 1575-1585. [CrossRef]

68. Zhu, J.; Ren, Z.-D.; Liu, Y.; Zhao, L.; Wu, Y. 6-Allyl-8-methoxy-3-phenyl-3,4-dihydro-2H-benzo[e][1,3]oxazine. Acta Crystallogr. Sect. E 2011, 67, o2056. [CrossRef] [PubMed]

69. Ranjith, S.; Thenmozhi, S.; Manikannan, R.; Muthusubramanian, S.; Subbiahpandi, A. 3,3'-(p-phenyl-ene)bis-(3,4-dihydro-2H-1,3benzoxazine). Acta Crystallogr. Sect. E 2009, 65, o581. [CrossRef]

70. Huerta, R.; Toscano, R.A.; Castillo, I. 1,4-Bis(8-tert-butyl-6-methyl-4H-1,3-benzoxazin-3-yl)benzene. Acta Crystallogr. Sect. E 2006, 62, o2938-o2940. [CrossRef]

71. Etter, M.C.; Macdonald, J.C.; Bernstein, J. Graph-Set analysis of hydrogen-bond patterns in organic crystals. Acta Crystallogr. Sect. $B$ 1990, 46, 256-262. [CrossRef]

72. Bernstein, J.; Shimoni, L.; Davis, R.E.; Chang, N.-L. Graph set analysis of hydrogen-bond patterns in organic crystals. Recent developments and applications. Acta Crystallogr. Sect. A 1993, 49, c164. [CrossRef]

73. Grell, J.; Bernstein, J.; Tinhofer, G. Graph-Set analysis of hydrogen-bond patterns: Some mathematical concepts. Acta Crystallogr. Sect. B 1999, 55, 1030-1043. [CrossRef]

74. Hirshfeld, F.L. Bonded-atom fragments for describing molecular charge densities. Theor. Chim. Acta 1977, 44, 129-138. [CrossRef]

75. Spackman, M.A.; Jayatilaka, D. Hirshfeld surface analysis. CrystEngComm 2009, 11, 19-32. [CrossRef]

76. Turner, M.J.; McKinnon, J.J.; Wolff, S.K.; Grimwood, D.J.; Spackman, P.R.; Jayatilaka, D.; Spackman, M.A. Crystal Explorer 17; The University of Western Australia: Crawley, Australia, 2017.

77. McKinnon, J.J.; Jayatilaka, D.; Spackman, M.A. Towards quantitative analysis of intermolecular interactions with Hirshfeld surfaces. Chem. Commun. 2007, 3814-3816. [CrossRef]

78. Maliszewsk Paczkowski, I.; Lange Coelho, F.; Franciscato Campo, L. 2,1,3-Benzothiadiazole dyes conjugated with benzothiazole and benzoxazole: Synthesis, solvatochromism and solid-state properties. J. Mol. Liq. 2020, 319, 114277. [CrossRef]

79. Affeldt, R.F.; De Amorim Borges, A.C.; Russowsky, D.; Severo Rodembusch, F. Synthesis and fluorescence properties of benzoxazole-1,4-dihydropyridine dyads achieved by a multicomponent reaction. New J. Chem. 2014, 38, 4607-4614. [CrossRef]

80. Chen, W.-H.; Pang, Y. Excited-State intramolecular proton transfer in 2-(2',6'-dihydroxyphenyl)benzoxazole: Effect of dual hydrogen bonding on the optical properties. Tetrahedron Lett. 2010, 51, 1914-1918. [CrossRef]

81. Adamo, C.; Jacquemin, D. The calculations of excited-state properties with Time-Dependent Density Functional Theory. Chem. Soc. Rev. 2013, 42, 845-856. [CrossRef] [PubMed] 